\title{
A total quasi-steady-state formulation of substrate uptake kinetics in complex networks and an example application to microbial litter decomposition
}

\author{
J. Y. Tang and W. J. Riley \\ Earth Science Division, Lawrence Berkeley National Laboratory (LBL), Berkeley, CA, USA \\ Correspondence to: J. Y. Tang (jinyuntang@lbl.gov)
}

Received: 21 May 2013 - Published in Biogeosciences Discuss.: 28 June 2013

Revised: 27 September 2013 - Accepted: 17 November 2013 - Published: 16 December 2013

\begin{abstract}
We demonstrate that substrate uptake kinetics in any consumer-substrate network subject to the total quasisteady-state assumption can be formulated as an equilibrium chemistry (EC) problem. If the consumer-substrate complexes equilibrate much faster than other metabolic processes, then the relationships between consumers, substrates, and consumer-substrate complexes are in quasiequilibrium and the change of a given total substrate (free plus consumer-bounded) is determined by the degradation of all its consumer-substrate complexes. In this EC formulation, the corresponding equilibrium reaction constants are the conventional Michaelis-Menten (MM) substrate affinity constants. When all of the elements in a given network are either consumer or substrate (but not both), we derived a firstorder accurate EC approximation (ECA). The ECA kinetics is compatible with almost every existing extension of MM kinetics. In particular, for microbial organic matter decomposition modeling, ECA kinetics explicitly predicts a specific microbe's uptake for a specific substrate as a function of the microbe's affinity for the substrate, other microbes' affinity for the substrate, and the shielding effect on substrate uptake by environmental factors, such as mineral surface adsorption.

By taking the EC solution as a reference, we evaluated $\mathrm{MM}$ and ECA kinetics for their abilities to represent several differently configured enzyme-substrate reaction networks. In applying the ECA and MM kinetics to microbial models of different complexities, we found (i) both the ECA and MM kinetics accurately reproduced the EC solution when multiple microbes are competing for a single substrate; (ii) ECA outperformed MM kinetics in reproducing the EC solution when a single microbe is feeding on multiple substrates; (iii)
\end{abstract}

the MM kinetics failed, while the ECA kinetics succeeded, in reproducing the $\mathrm{EC}$ solution when multiple consumers (i.e., microbes and mineral surfaces) were competing for multiple substrates. We then applied the EC and ECA kinetics to a guild based C-only microbial litter decomposition model and found that both approaches successfully simulated the commonly observed (i) two-phase temporal evolution of the decomposition dynamics; (ii) final asymptotic convergence of the lignocellulose index to a constant that depends on initial litter chemistry and microbial community structure; and (iii) microbial biomass proportion of total organic biomass (litter plus microbes). In contrast, the MM kinetics failed to realistically predict these metrics. We therefore conclude that the ECA kinetics are more robust than the MM kinetics in representing complex microbial, $\mathrm{C}$ substrate, and mineral surface interactions. Finally, we discuss how these concepts can be applied to other consumer-substrate networks.

\section{Introduction}

Many natural systems involve processes that can be modeled as consumer-substrate (or consumer-resource in a broader context) interactions. These interactions include, but are not limited to (i) multicomponent adsorption in aqueous chemistry (e.g., Jennings et al., 1982; Choy et al., 2000); (ii) aerosol and cloud droplet interactions in atmospheric chemistry (e.g., Pilinis et al., 1987; Jacobson et al., 1996); (iii) protein interaction networks in molecular biology (e.g., Childs and Bardsley, 1974; Ciliberto et al., 2007); and (iv) many more in natural ecosystems, such as plant-microbe 
competition for inorganic nitrogen and phosphorus (e.g., Reynolds and Pacala, 1993; Lambers et al., 2009), plant competition for light (e.g., Dybzinski et al., 2011), microbial competition for carbon substrates and mineral nutrients (e.g., Caperon, 1967; Moorhead and Sinsabaugh, 2006; Allison, 2012; Bouskill et al., 2012), algae competition for mineral nutrients (e.g., Tilman, 1977; Follows et al., 2007), and predator competition for prey (e.g., Holling, 1959a; Arditi and Ginzburg, 1989; Ginzburg and Akcakaya, 1992; Vayenas and Pavlou, 1999; Abrams and Ginzburg, 2000; Koen-Alonso, 2007). Because of this prevalence of consumer-substrate interactions in natural systems, particularly in ecosystem dynamics, many mathematical developments have been proposed to interpret and predict ecosystem behavior under a wide range of environmental and biological conditions (e.g., Lotka, 1923; Volterra, 1926; Holling, 1959b; Campbell, 1961; Murdoch, 1973; Williams, 1973; Tilman, 1977; Pasciak and Gavis, 1974; Persson et al., 1998; Maggi et al., 2008; Bonachela et al., 2011; Bouskill et al., 2012). In this study, we present developments focusing on the consumer-substrate network that regulates organic matter decomposition. However, our results should be applicable to any problem that can be similarly formulated as a consumersubstrate network.

In general, the growth of any biological organism minimally involves two steps: (i) substrate uptake and (ii) substrate assimilation. Once a substrate is captured, it is assimilated to produce energy and biomass for a series of metabolic processes, including, but not limited to, cell maintenance, enzyme production, cell division, and reproduction. Therefore, explicit modeling of the interactions between many consumers, substrates, and their habitats requires a consistent mathematical representation of substrate uptake under a wide range of biotic and abiotic conditions. Among the many existing substrate uptake kinetics (Hill, 1910; Michaelis and Menten, 1913; Burnett, 1954; Holling, 1959b; Cleland, 1963), the Michaelis-Menten (MM) kinetics (or equivalently Monod (Monod, 1949) or Holling's type II (Holling, 1959b) kinetics) is the most widely applied because of its simple form, solid theoretical foundation (e.g., Liu, 2007), and successes under a wide range of conditions (e.g., Holling, 1959b; Tilman, 1977; Reynolds and Pacala, 1993; Legovic and Cruzado, 1997; Hall, 2004; Kou, 2005; Riley and Matson 2000; Maggi et al., 2008; Allison, 2012).

In their seminal paper, Michaelis and Menten (1913) assumed that enzymes and substrates adsorb to each other to form enzyme-substrate complexes. By assuming the enzyme-substrate complex is of a much lower concentration than that of the substrate, they obtained, by law of mass actions, the so-called MM kinetics, which states

$v=\frac{V_{\max } S}{K_{\mathrm{S}}+S}$

where $v\left(\mathrm{~mol} \mathrm{~s}^{-1}\right)$ is the substrate uptake rate, $V_{\max }\left(\mathrm{mol} \mathrm{s}^{-1}\right)$ is the maximum substrate uptake rate, $K_{\mathrm{S}}\left(\mathrm{mol} \mathrm{m}^{-3}\right)$ is the half saturation (or substrate affinity) constant, and $S$ $\left(\mathrm{mol} \mathrm{m}^{-3}\right)$ is the free substrate concentration (a full list of symbols is given at the end of the text). Later, Briggs and Haldane (1925) derived Eq. (1) from the enzyme-catalyzed reaction:

$S+E \stackrel{k_{1}^{+}}{\stackrel{k_{1}^{-}}{\rightarrow}} \stackrel{k_{2}^{+}}{\rightarrow} P+E$

where $E\left(\mathrm{~mol} \mathrm{~m}^{-3}\right)$ is (free) enzyme, $C\left(\mathrm{~mol} \mathrm{~m}^{-3}\right)$ is enzyme-substrate complex from binding (free) substrate $S$ to enzyme $E, P$ is the product $\left(\mathrm{mol} \mathrm{m}^{-3}\right.$ ) resulting from the irreversible part of reaction (2), $k_{1}^{+}\left(\mathrm{m}^{3} \mathrm{~mol}^{-1} \mathrm{~s}^{-1}\right)$ and $k_{2}^{+}$ $\left(\mathrm{s}^{-1}\right)$ are forward reaction coefficients, $k_{1}^{-}\left(\mathrm{s}^{-1}\right)$ is the backward reaction coefficient, and $K_{\mathrm{S}}=\left(k_{1}^{-}+k_{2}^{+}\right) / k_{1}^{+}$. Later studies (e.g., Segel and Slemrod, 1989; Schnell and Maini, 2000) indicated that Eq. (1) was obtained with the standard quasi-steady-state assumption (sQSSA), which states that $\frac{\mathrm{d} C}{\mathrm{~d} t} \approx 0$ and $\frac{\mathrm{d} S}{\mathrm{~d} t}=-k_{1}^{+} S E+k_{1}^{-} C$ (note that $\frac{\mathrm{d} S}{\mathrm{~d} t}$ is the changing rate of the free substrate, which is different from the total substrate being used in the total quasi-steady-state assumption (tQSSA) to be introduced later). Equation (1) is valid only when $S+K_{\mathrm{S}} \gg E_{\mathrm{T}}$, where $E_{\mathrm{T}}$ is the total enzyme concentration including both free and substrate-bound.

The MM kinetics has been successful in many applications, but there are also many studies demonstrating that modifications must be made to account for discrepancies between predictions from applying Eq. (1) and observations (e.g., Cha and Cha, 1965; Williams, 1973; Suzuki et al., 1989; Maggi and Riley, 2009; Druhan et al., 2012). For instance, Cha and Cha (1965), in studying cyclic enzyme systems, noticed that the substrate uptake kinetics, when approximated with first order accuracy, should be

$v=\frac{V_{\max } S_{\mathrm{T}}}{K_{\mathrm{S}}+E_{\mathrm{T}}+S_{\mathrm{T}}}$.

Others have obtained Eq. (3), or a similar form, for various problems (e.g., Reiner, 1969; Segel, 1975; Schulz, 1994; Borghans and De Boer, 1995; Borghans et al., 1996; Schnell and Maini, 2000; Wang and Post, 2013). In particular, Borghans et al. (1996), using the total quasi-steady-state approximation (tQSSA; which also assumes $\frac{\mathrm{d} C}{\mathrm{~d} t} \approx 0$, but defines a total substrate $S_{\mathrm{T}}=S+C$ and uses $\frac{\mathrm{d} S_{\mathrm{T}}}{\mathrm{d} t}=-k_{2}^{+} C$ ), showed Eq. (3) is valid if $k_{2}^{+} E_{\mathrm{T}}<<k_{1}^{+}\left(K_{\mathrm{S}}+E_{\mathrm{T}}+S_{\mathrm{T}}\right)^{2}$.

Equation (3) is of good accuracy for a much wider range of substrate and enzyme concentrations than Eq. (1). It also alleviates the problem that $v \rightarrow \infty$ as $E_{\mathrm{T}} \rightarrow \infty$ if Eq. (1) is used (note $V_{\max } \propto E_{\mathrm{T}}$ ). In addition, when applied to predatorprey systems (i.e., predator $=E$, prey $=S$ ), Eq. (3) predicts predation depends on both (i) the ratio between predator and prey density and (ii) prey density. While we have not found an example in the literature of Eq. (3) being evaluated with predation data, a few studies (e.g., Vucetich et al., 2002; Schenk et al., 2005) indicated the predation rate is not only 
ratio dependent, as proposed in Arditi and Ginzburg (1989), nor only density dependent, as implied by MM kinetics.

Extension of the MM kinetics to more general cases such as (i) one enzyme (henceforth, without loss of generality, we use enzymes as the consumers) competing for multiple substrates (Schnell and Mendoza, 2000; Koen-Alonso, 2007; Maggi and Riley, 2009), (ii) multiple enzymes competing for one substrate (Suzuki et al., 1989; De Boer and Perelson, 1995; Grant et al., 1993), and (iii) many enzymes interacting with many substrates (De Boer and Perelson, 1994; Ciliberto et al., 2007). Though the most general case (iii) has been attempted in various contexts, we are not aware of any analytical representation presented in the literature.

An analytically and computationally tractable formulation for case (iii) mentioned above is practically important to solve many problems, such as trait-based modeling of microbial ecosystems (Follows et al., 2007; Allison, 2012; Bouskill et al. 2012) and complicated trophic networks (Lindeman, 1942). Since, in a trophic network, a predator's predation on a prey can be practically considered as a random pairing process between the predator and prey, and the feeding process is just the conversion of a prey into internal biomass of the predator (e.g., Caperon, 1967), the uptake and assimilation of a substrate in a predator-prey system can thus be analogically described by Eq. (2), with the predator's rates of prey foraging, prey escape, and prey handling (i.e., activities like killing and eating) described, respectively, by parameters $k_{1}^{+}$, $k_{1}^{-}$, and $k_{2}^{+}$.

Trait-based modeling of a general microbial ecosystem is different than that of a trophic network due to the unavoidable interactions between substrates and the aqueous chemical environment. Particularly, the soil microbial ecosystem is further complicated by substrate interactions with various adsorption surfaces (e.g., mineral surfaces and biochar). Existing approaches often model the interactions between microbial substrate uptake and aqueous chemistry and mineral surface interactions in separate steps, while ignoring the mathematical similarities between microbial substrate uptake, aqueous chemistry, and mineral surface interactions (e.g., Maggi et al., 2008; Gu et al., 2009). Interestingly, Michaelis and Menten (1913) recognized that Eq. (1) could be derived from the law of mass action by assuming equilibrium between the formation and degradation of the enzymesubstrate complexes (though a formal mathematical treatment was done by Briggs and Haldane, 1925). In their study, Michaelis and Menten also considered a single enzyme that could bind with three different substrates and obtained a modified substrate uptake function under the assumption of negligible enzyme-substrate complex concentration compared to substrates. Therefore, the apparent mathematical equivalence between the enzyme-substrate binding process and that of the chemical interaction between mineral (or organic) surfaces and aqueous chemical species, where the latter can usually be described as being in equilibrium (e.g.,
Jennings, 1982; Wang et al., 2013), should provide a framework to model the biotic substrate uptake kinetics and abiotic chemistry simultaneously. If such a framework can be identified, it will consistently describe the substrate uptake by a microbe (or a consumer in a broader definition) as a function of the microbe's traits, traits of other microbes, and the impacts from different abiotic environmental factors. Such a framework will fit well with the idea of game theory (that is often used to describe biological evolutionary systems), which states "the fitness of an individual is simultaneously influenced by its own strategy, the strategies of others, and other features of the abiotic and biotic environment" (McGill and Brown, 2007).

In this study, we propose a general approach to modeling a consumer-substrate network that has an arbitrary but finite number of consumers and substrates, and present its analytical approximations under some simplified conditions. We organize the paper as follows: Sect. 2 presents the theoretical aspects of our approach and the design of illustrative numerical experiments to evaluate our approach and an application to the modeling of microbial litter decomposition; Sect. 3 presents relevant results and discusses the limitations and potential applications of our developments; and finally, Sect. 4 summarizes the major findings of this study.

\section{Methods}

In this section, we first derive the full equilibrium chemistry (EC) formulation of the consumer-substrate network and its analytical approximation (ECA) that is at best first order accurate. We then describe illustrative numerical experiments that are used to evaluate the classical MM kinetics and the ECA kinetics in modeling complex transient consumersubstrate networks, including a simple model exercise of the microbial litter decomposition problem.

\subsection{An equilibrium chemistry based formulation of consumer-substrate networks}

We consider here enzymes as the consumers in our consumer-substrate network, so that our derivation is based on enzyme kinetics. However, the substrate uptake kinetics in other systems can be represented analogously as long as the following assumptions hold: (i) consumers and substrates are well mixed in their environment; (ii) consumers and substrates only exist in free and complexed states (which could broadly include organic and inorganic chemical adsorption, and even engagement in social activities for predator-prey systems); and (iii) the equilibration between formation and degradation of consumer-substrate complexes is much faster than the change of total substrates (free plus complexed) and total enzymes (free plus complexed) due to all possible biotic and abiotic sinks and sources. Assumption (i) is commonly made in environmental biogeochemistry, although it can be 
violated at small scales (e.g., Molins et al., 2012) or under water-stressed conditions where substrates can become disconnected from consumers (e.g., Schimel et al., 2011). All consumer-substrate networks typically satisfy assumption (ii). A rigorous proof is still lacking for assumption (iii), but Kumar and Josie (2011) showed with mathematical rigor that it holds well for some special consumer-substrate networks, Ciliberto et al. (2007) showed it worked well for proteinprotein interactive networks, and the MM kinetics (which also applies assumption; iii) has demonstrated its success in numerous cases (but MM kinetics fails for some cases such as isotopic fractionation; Maggi and Riley, 2009; Druhan et al., 2012). However, Maggi and Riley (2009) concluded that if assumption (iii) was paired with the SQSSA, the resultant substrate kinetics failed to describe the isotopic fractionation at high enzyme concentrations.

With these three assumptions, we consider an enzyme $\left(E_{j}, j=1, \cdots, J\right)$ catalyzed reaction that converts a substrate $\left(S_{i}, i=1, \ldots, I\right)$ into a final product $P_{i j}$ :

$S_{i}+E_{j} \underset{k_{i j, 1}^{+}}{\stackrel{k_{i j, 1}^{+}}{\longrightarrow}} C_{i j} \stackrel{k_{i j, 2}^{+}}{\rightarrow} E_{j}+P_{i j}$,

where $k_{i j, 1}^{+}\left(\mathrm{m}^{3} \mathrm{~mol}^{-1} \mathrm{~s}^{-1}\right)$ and $k_{i j, 2}^{+}\left(\mathrm{s}^{-1}\right)$ are reaction coefficients for the forward reactions, $k_{i j, 1}^{-}\left(\mathrm{s}^{-1}\right)$ is the reaction coefficient for the reverse reactions, and $C_{i j}\left(\mathrm{~mol} \mathrm{~m}^{-3}\right)$ is the enzyme-substrate complex formed by binding $S_{i}$ with $E_{j}$.

Under the SQSSA (also the tQSSA), $C_{i j}$ is constant during a modeling (or measurement) time step (Michaelis and Menten, 1913), which leads to

$S_{i} E_{j} k_{i j, 1}^{+}=\left(k_{i j, 1}^{-}+k_{i j, 2}^{+}\right) C_{i j}$

and can be rewritten as

$K_{\mathrm{S}, i j}=\frac{k_{i j, 1}^{-}+k_{i j, 2}^{+}}{k_{i j, 1}^{+}}=\frac{S_{i} E_{j}}{C_{i j} .}$

Therefore, Eq. (5) describes the following chemical equilibrium:

$S_{i}+E_{j} \stackrel{K_{\mathrm{S}, i j}}{\leftrightarrow} C_{i j}$

By taking the remaining procedures to obtain the MM kinetics, it can be shown that $K_{\mathrm{S}, i j}\left(\mathrm{~mol} \mathrm{~m}^{-3}\right)$ is just the substrate affinity (or half saturation) constant (see Eq. 1 in Michaelis and Menten, 1913). Note, as $K_{\mathrm{S}, i j} \rightarrow \infty$, the complexation between substrate $S_{i}$ and enzyme $E_{j}$ becomes increasingly difficult.

For a reaction network that involves many substrates and enzymes, one can write a chemical equilibrium for each reaction in the form of Eq. (7). Therefore, the reaction network can be viewed as an equilibrium chemistry (EC) problem, which have been intensively studied in atmospheric aerosol chemistry (Pilinis et al., 1987; Jacobson et al., 1996; Jacobson, 1999) and reactive transport modeling (e.g., Jennings et al., 1982). This EC formulation enables one to use existing software, such as MINTEQ (Felmy et al., 1984), SOILCHEM (Sposito and Coves, 1988), and EQUISOLV (Jacobson, 1999), to solve for all the substrate-enzyme complexes and then apply the equation

$\frac{\mathrm{d} P_{i j}}{\mathrm{~d} t}=k_{i j, 2}^{+} C_{i j}$

to compute the production rate of $P_{i j}$ from processing of substrate $S_{i}$ by enzyme $E_{j}$.

Under the sQSSA, the change of a free substrate $S_{i}$ due to the degradation of all its relevant enzyme-substrate complexes is:

$\frac{\mathrm{d} S_{i}}{\mathrm{~d} t}=-\sum_{k=1}^{k=J}\left(k_{i k, 1}^{+} S_{i} E_{k}-k_{i k, 1}^{-} C_{i k}\right)$.

Under the tQSSA (Borghans et al., 1996), one defines

$S_{i, \mathrm{~T}}=S_{i}+\sum_{k=1}^{k=J} C_{i k}$,

and then, by combing Eqs. (6), (9) and (10), one obtains

$\frac{\mathrm{d} S_{i, \mathrm{~T}}}{\mathrm{~d} t}=-\sum_{k=1}^{k=J} k_{i k, 2}^{+} C_{i k}$.

We then obtain the full EC formulation by combining Eqs. (6), (11), and the enzyme mass balance:

$E_{j, \mathrm{~T}}=E_{j}+\sum_{k=1}^{k=I} C_{k j}$.

We note that if $k_{i j, 2}^{+}=0$, then the complex formed with enzyme $E_{j}$ effectively becomes a shelter for any substrate it can bind to. This constraint allows us to quantify the impact of different adsorption surfaces (e.g., mineral surfaces and biochar) on microbial substrate uptake in a consumersubstrate network. Further, with the great flexibility provided by the EC formulation (Jennings et al., 1982; Jacobson, 1999), one could simultaneously simulate biotic and abiotic interactions for arbitrarily complex networks, subjected to computational resource constraints. In addition, we note that the development by Cleland (1963) and the binding strategy in the synthesizing unit approach by Kooijman (1998) are just special cases of the EC formulation.

\subsection{An at-best first-order accurate analytical approximation to the equilibrium chemistry based formulation for some special consumer-substrate networks}

If a consumer-substrate network satisfies two conditions - (i) binding does not occur between substrates or between consumers; and (ii) a consumer-substrate complex, once formed, 
does not bind with another substrate or consumer to form new complexes - we find an at-best first-order accurate equilibrium chemistry approximation (ECA) (see Appendix A for derivation details):

$$
C_{i j}=\frac{S_{i, \mathrm{~T}} E_{j, \mathrm{~T}}}{K_{\mathrm{S}, i j}\left(1+\sum_{k=1}^{k=I} \frac{S_{k, \mathrm{~T}}}{K_{\mathrm{S}, k j}}+\sum_{k=1}^{k=J} \frac{E_{k, \mathrm{~T}}}{K_{\mathrm{S}, i k}}\right)},
$$

where we have assumed the reaction network includes $I$ substrates and $J$ enzymes (a visualizing way to write Eq. 13 is shown in Fig. 1). By combining Eq. (11) with Eq. (13), this ECA kinetics states that the uptake of substrate $S_{i}$ by consumer $E_{j}$ depends on (i) the characteristics of the consumer and substrate of interest (through $K_{\mathrm{S}, i j}$ ) and (ii) the characteristics of abiotic and biotic interactions with other substrates and consumers (through $K_{\mathrm{S}, k j}$ and $K_{\mathrm{S}, i k}$ ). In particular, when applied to predator-prey systems, the ECA kinetics indicates that predation rate is neither ratio nor density dependent, a problem that is yet still under debate (Arditi and Ginzburg, 1989; Abrams, 2000; Vucetich et al., 2002; Schenk et al., 2005; Kratina et al., 2009). Next, we derive a few interesting results from Eq. (13).

First, for a reaction that has only one enzyme interacting with one substrate, we have

$C_{11}=\frac{S_{1, \mathrm{~T}} E_{1, \mathrm{~T}}}{K_{\mathrm{S}, 11}+S_{1, \mathrm{~T}}+E_{1, \mathrm{~T}}}$,

which is equivalent to Eq. (3). When the substrate concentration is much higher than the enzyme concentration, such that the microbial process barely changes the total substrate concentration in the temporal window of interest, $K_{\mathrm{S}, 11}+S_{1, \mathrm{~T}}$ is almost constant, and Eq. (14) becomes the reverse MM kinetics (Schimel and Wintraub, 2003). When the substrate is changing significantly while the overall enzyme concentration is much lower than the substrate, so that $K_{\mathrm{S}, 11}+E_{1, \mathrm{~T}}$ is almost constant, Eq. (14) is reduced to the classical MM kinetics (Michaelis and Menten, 1913).

Second, when enzyme concentrations are very high, more inactive enzymes (e.g., transporters of dead cells) will compete with the active enzymes for substrate adsorption, consequently introducing an inhibition. By treating the active and inactive fractions of an enzyme as two different enzymes, Eq. (14) can be reformulated as

$C_{11}=\frac{S_{1, \mathrm{~T}} E_{1, \mathrm{~T}}}{S_{1, \mathrm{~T}}+K_{\mathrm{S}, 11}\left(1+\frac{E_{1, \mathrm{~T}}}{K_{\mathrm{S}, 11}}+\frac{E_{2, \mathrm{~T}}}{K_{\mathrm{S}, 12}}\right)}$,

where $E_{1, \mathrm{~T}}\left(\mathrm{~mol} \mathrm{~m}^{-3}\right)$ and $E_{2, \mathrm{~T}}\left(\mathrm{~mol} \mathrm{~m}^{-3}\right)$ are the total concentrations of the active and inactive enzymes, respectively. By taking $\alpha_{1}$ as the transient partitioning coefficient between active and inactive enzyme concentrations (i.e., $E_{1, \mathrm{~T}}=\alpha_{1} E_{\mathrm{T}}$ and $E_{2, \mathrm{~T}}=\left(1-\alpha_{1}\right) E_{\mathrm{T}}$, with $\left.E_{\mathrm{T}}=E_{1, \mathrm{~T}}+E_{2, \mathrm{~T}}\right)$, Eq. (14) can be rewritten as

\begin{tabular}{|c|ccccccc|}
\hline & $E_{1}$ & $\ldots$ & $E_{j-1}$ & $E_{j}$ & $E_{j+1}$ & $\ldots$ & $E_{J}$ \\
\hline$S_{1}$ & $K_{S, 11}$ & $\ldots$ & $K_{S, 1, j-1}$ & $K_{S, 1, j}$ & $K_{S, 1, j+1}$ & $\ldots$ & $K_{S, I J}$ \\
$\vdots$ & $\vdots$ & $\ddots$ & $\vdots$ & $\vdots$ & $\vdots$ & $\ddots$ & $\vdots$ \\
$S_{i-1}$ & $K_{S, i-1,1}$ & $\ldots$ & $K_{S, i-1, j-1}$ & $K_{S, i-1, j}$ & $K_{S, i-1, j+1}$ & $\ldots$ & $K_{S, i-1, J}$ \\
$S_{i}$ & $K_{S, i 1}$ & $\ldots$ & $K_{S, i, j-1}$ & $K_{S, i j}$ & $K_{S, i, j+1}$ & $\ldots$ & $K_{S, J J}$ \\
$S_{i+1}$ & $K_{S, i+1,1}$ & $\ldots$ & $K_{S, i+1, j-1}$ & $K_{S, i+1, j}$ & $K_{S, i+1, j+1}$ & $\ldots$ & $K_{S, i+1, J}$ \\
$\vdots$ & $\vdots$ & $\ddots$ & $\vdots$ & $\vdots$ & $\vdots$ & $\ddots$ & $\vdots$ \\
$S_{I}$ & $K_{S, l 1}$ & $\ldots$ & $K_{S, I, j-1}$ & $K_{S, l, j}$ & $K_{S, I, j+1}$ & $\ldots$ & $K_{S, I J}$ \\
\hline
\end{tabular}

Fig. 1. A matrix-based representation of the parameter configuration for the ECA substrate kinetics (Eq. 13).

$$
\begin{aligned}
C_{11} & =\frac{\alpha_{1} S_{1, \mathrm{~T}} E_{\mathrm{T}}}{S_{1, \mathrm{~T}}+K_{\mathrm{S}, 11}\left[1+\left(\frac{\alpha_{1}}{K_{\mathrm{S}, 11}}+\frac{1-\alpha_{1}}{K_{\mathrm{S}, 12}}\right) E_{\mathrm{T}}\right]} \\
& =\frac{\alpha_{1} S_{1, \mathrm{~T}} E_{\mathrm{T}}}{S_{1, \mathrm{~T}}+K_{\mathrm{S}, 11}\left(1+\frac{E_{\mathrm{T}}}{K_{I}}\right)},
\end{aligned}
$$

where $K_{I}=\left(\frac{\alpha_{1}}{K_{\mathrm{S}, 11}}+\frac{1-\alpha_{1}}{K_{\mathrm{S}, 12}}\right)^{-1}$ and the term after the second equal sign is equivalent to Eq. (2) derived in Suzuki et al. (1989), where they used it to explain the inhibition effect from ineffective binding between substrate and inactive cells. We point out that Eq. (16) could be used to represent the inhibition effect from soil minerals, which can compete for substrates analogously as an ineffective enzyme (that does not result in a new chemical product but may protect the substrates from microbial attack).

Third, for the case of many enzymes competing for a single substrate, Eq. (13) can be reduced to

$$
C_{1 j}=\frac{S_{1, \mathrm{~T}} E_{j, \mathrm{~T}}}{K_{\mathrm{S}, 1 j}\left(1+\sum_{k=1}^{k=J} \frac{E_{k, \mathrm{~T}}}{K_{\mathrm{S}, 1 k}}\right)+S_{1, \mathrm{~T}}} .
$$

Grant et al. (1993) used a variant of Eq. (17) to represent the competitive uptake of a substrate in the presence of many microbes (see their Eqs. 3 and 4). However, Grant et al. (1993) directly generalized the results by Suzuki et al. (1989) (without explicit derivation) and also implicitly assumed that there are ineffective enzymes competing for substrates. With this latter assumption, Eq. (17) can rewritten as

$$
C_{1 j}=\frac{\alpha_{j} S_{1, \mathrm{~T}} E_{j, \mathrm{~T}}}{K_{\mathrm{S}, 1 j}\left(1+\sum_{k=1}^{k=J} \frac{E_{k, \mathrm{~T}}}{K_{I, 1 k}}\right)+S_{1, \mathrm{~T}}},
$$


where $\alpha_{j}$ is the transient active fraction of enzyme $E_{j}$ and the inhibition constants are

$K_{I, 1 k}=\left(\frac{\alpha_{k}}{K_{\mathrm{S}, 1 k}}+\frac{1-\alpha_{k}}{K_{\mathrm{S}, 1 k, \mathrm{~d}}}\right)^{-1}$,

where $K_{\mathrm{S}, 1 k}$ and $K_{S, 1 k, \mathrm{~d}}$ are affinity constants of the active and inactive enzyme $E_{k}$, respectively. Note that the value of $J$ in Eq. (18) is half of that in Eq. (17) since Eq. (18) groups the active and inactive fractions of an enzyme into one.

Fourth, in the case of a single enzyme interacting with many substrates, Eq. (13) is reduced to

$$
C_{i 1}=\frac{S_{i, \mathrm{~T}} E_{1, \mathrm{~T}}}{K_{\mathrm{S}, i 1}\left(1+\sum_{k=1}^{k=I} \frac{S_{k, \mathrm{~T}}}{K_{\mathrm{S}, k 1}}\right)+E_{1, \mathrm{~T}}} .
$$

When $E_{1, \mathrm{~T}}$ is constant, Eq. (20) can be equivalently rewritten as

$$
C_{i 1}=\frac{S_{i, \mathrm{~T}} E_{1, \mathrm{~T}}}{\hat{K}_{\mathrm{S}, i 1}\left(1+\frac{K_{\mathrm{S}, i 1}}{\hat{K}_{\mathrm{S}, i 1}} \sum_{k=1}^{k=I} \frac{S_{k, \mathrm{~T}}}{K_{\mathrm{S}, k 1}}\right)},
$$

where $\hat{K}_{\mathrm{S}, i 1}=K_{\mathrm{S}, i 1}+E_{1, \mathrm{~T}}$. If further assuming $\hat{K}_{\mathrm{S}, i 1} \gg$ $E_{1, \mathrm{~T}}$, such that $\hat{K}_{\mathrm{S}, i 1}=K_{\mathrm{S}, i 1}$, then Eq. (21) is just the multicomponent Langmuir isotherm for multicomponent adsorption in aqueous chemistry (e.g., Choy et al., 2000) and has been used for multi-prey predation in predator-prey models (e.g., Murdoch, 1973). We also note the multicomponent Langmuir isotherm is based on SQSSA.

If there are only two substrates (i.e., $I=2$ ), Eq. (20) can be rewritten as

$$
\begin{aligned}
C_{11} & =\frac{S_{1, \mathrm{~T}} E_{1, \mathrm{~T}} / K_{\mathrm{S}, 11}}{1+\frac{S_{1, \mathrm{~T}}}{K_{\mathrm{S}, 11}}+\frac{S_{2, \mathrm{~T}}}{K_{\mathrm{S}, 21}}+\frac{E_{1, \mathrm{~T}}}{K_{\mathrm{S}, 11}}} \\
C_{21} & =\frac{S_{2, \mathrm{~T}} E_{1, \mathrm{~T}} / K_{\mathrm{S}, 21}}{1+\frac{S_{1, \mathrm{~T}}}{K_{\mathrm{S}, 11}}+\frac{S_{2, \mathrm{~T}}}{K_{\mathrm{S}, 21}}+\frac{E_{1, \mathrm{~T}}}{K_{\mathrm{S}, 21}}} .
\end{aligned}
$$

Then by further assuming $E_{1, \mathrm{~T}} / K_{\mathrm{S}, 11}$ and $E_{1, \mathrm{~T}} / K_{\mathrm{S}, 21}$ are much smaller than the other terms, one obtains the Eq. (20) in Maggi and Riley (2009). Druhan et al. (2012) have used Eq. (20) by Maggi and Riley (2009) to explain sulfur isotope fractionation in a field subsurface acetate amendment experiment. Our Eq. (22) is based on the tQSSA, which makes it valid for a wider range of substrate and enzyme concentrations. This contrasts our Eq. (22) with Maggi and Riley's Eq. (20), which is based on the SQSSA, and was found to incorrectly predict isotopic fractionations when enzyme concentrations were comparable or higher than substrate concentrations.

\subsection{Extension to other inhibitory mechanisms}

The EC and ECA kinetics inherently account for competitive inhibition (inhibition mechanism (i)), including product competitive inhibition. For enzyme kinetics or, more broadly, microbe-substrate networks, there are three additional main inhibitory mechanisms often considered (Cornish-Bowden, 1995): (ii) uncompetitive inhibition (inhibitor binds to the enzyme-substrate complex to make the binding ineffective); (iii) noncompetitive inhibition (inhibitor binds equally well to both free enzyme and enzyme-substrate complexes and reduces the number of effective bindings but does not affect the enzyme's substrate affinity); and (iv) mixed inhibition (a mixture of competitive and noncompetitive inhibition, but the inhibitor has different affinity for free enzyme and the enzyme-substrate complex).

The EC kinetics is compatible with all these four inhibitory mechanisms, as long as the reaction coefficients can be properly defined for all the inhibitor binding equations. However, the simplified ECA kinetics is only able to represent competitive and noncompetitive inhibition (with some modifications discussed below). Including mixed and noncompetitive inhibition is only possible when many substrates are competing for a single enzyme or vice versa (and the relevant mathematics is much more complicated than we have presented for competitive and noncompetitive inhibitions here). In addition, as will be demonstrated later (see the numerical experiments), even the ECA kinetics without inhibitory mechanisms (ii), (iii), and (iv) are not always highly accurate (compared to EC kinetics), nor can they be calibrated robustly due to parameterization equifinality (i.e., different combinations of parameters can result in very similar model predictions (e.g., Beven, 2006; Tang and Zhuang, 2008)). Since including these other inhibitory mechanisms (beside competitive inhibition) will generally introduce more parameters, making the simulations more uncertain, the gain in mechanistic representation is thus smaller than the loss of predictive capability.

Nevertheless, a first order approximation for the noncompetitive inhibition can be achieved by, first, modifying the substrate affinity coefficients (used in Eq. 13) that are subject to the inhibitors $I_{k}, k=1, \cdots, L$ as

$$
\tilde{K}_{\mathrm{S}, i j}=\frac{K_{\mathrm{S}, i j}}{\sum_{k=1}^{k=L} \frac{I_{k, \mathrm{~T}}}{K_{I, i j k}}+1},
$$

where $K_{I, i j k}, k=1, \ldots, L$ are the inhibition coefficients of each inhibitor on enzyme-substrate complex $C_{i j}$. In deriving Eq. (24) we assume that any two inhibitors cannot bind simultaneously to an enzyme-substrate complex.

Second, substituting the modified substrate affinity coefficients $\tilde{K}_{\mathrm{S}, i j}$ into Eq. (13), one obtains the enzyme-substrate complex concentration (under the influence of noncompetitive inhibition):

$$
\tilde{C}_{i j}=\frac{S_{i, \mathrm{~T}} E_{j, \mathrm{~T}}}{K_{\mathrm{S}, i j}\left(1+\sum_{k=1}^{k=I} \frac{S_{k, \mathrm{~T}}}{\tilde{K}_{\mathrm{S}, k j}}+\sum_{k=1}^{k=J} \frac{E_{k, \mathrm{~T}}}{\tilde{K}_{\mathrm{S}, i k}}\right)} .
$$




\subsection{Linking with microbial traits}

An appealing application of the EC and ECA kinetics is to trait-based modeling of marine and soil microorganisms (Follows et al., 2007; Litchman et al., 2007; Allison, 2012; Bouskill et al., 2012). In the trait-based modeling approach, parameters of the substrate uptake kinetics are determined by the microorganisms' traits, such as cell size and transporter density (e.g., Follows et al., 2007; Armstrong, 2008; Bonachela et al., 2011). Both the EC and ECA kinetics are compatible with such concepts, and the incorporation of these traits can be accomplished efficiently through the dynamic update of relevant microbial state variables in the numerical model. For instance, to consider the effect of cell size (which affects substrate diffusion between the environment and the cell) and transporter density (which affects processing rate and affinity to the substrate) on substrate uptake, one has the updated substrate uptake (see diagram shown in Fig. 2). With the stationary flux assumption (Pasciak and Gavis, 1974, 1975), one obtains the diffusive flux to a spherical cell as $\Phi_{\mathrm{D}}=4 \pi D_{i} r_{\mathrm{c}, j} n_{j}\left(S_{i}-\tilde{S}_{i}\right)$, where $D_{i}\left(\mathrm{~m}^{2} \mathrm{~s}^{-1}\right)$ is the diffusivity of the substrate $S_{i}$ in water (when in soil, this diffusivity depends on soil matric potential, soil structure, and temperature), $r_{\mathrm{c}, j}(\mathrm{~m})$ is the average size of cell $j$ (by assuming a spherical cell shape in the first order approximation), and $n_{j}$ (number of cells $\mathrm{m}^{-3}$ ) is the number density of cell $j$. The impact of advection on the flux $\Phi_{\mathrm{D}}$ can also be included using the dimensionless Sherwood number (KarpBoss et al., 1996), but that will not change our derivation essentially. Further assuming the internal substrate $\tilde{S}_{i}$ concentration (that is close to the cell) is also stationary (thus $\Phi_{\mathrm{D}}$ is equal to the net enzyme-substrate complex formation rate between $\tilde{S}_{i}$ and the cell's transporter), one obtains (as a first order approximation)

$\tilde{S}_{i}=\frac{4 \pi D_{i} r_{\mathrm{c}} n_{j} S_{i}}{k_{i j, 1}^{+} E_{j}+4 \pi D_{i} r_{\mathrm{c}} n_{j}} \approx \frac{4 \pi D_{i} r_{\mathrm{c}} n_{j} S_{i}}{k_{i j, 1}^{+} E_{j, \mathrm{~T}}+4 \pi D_{i} r_{\mathrm{c}} n_{j}}$,

where we have assumed the reverse dissociation of the enzyme-substrate complex $\left(k_{i j, 1}^{-}\right)$is negligible, $E_{j} \approx E_{j, \mathrm{~T}}$, and the changing rate of the enzyme (or transporter) abundance due to new growth is much slower than the enzymesubstrate complex equilibration rate. Therefore, one can represent the enzyme-substrate complex with Eq. (7) and a modified equilibrium coefficient:

$$
\tilde{K}_{\mathrm{S}, i j}=\frac{k_{i j, 1}^{-}+k_{i j, 2}^{+}}{k_{i j, 1}^{+}}\left(1+\frac{k_{i j, 1}^{+} E_{j, \mathrm{~T}}}{4 \pi D_{i} r_{\mathrm{c}, j} n_{j}}\right)
$$

which leads to a new representation of the substrate affinity parameter for Eq. (13) as

$$
\tilde{K}_{\mathrm{S}, i j}=K_{\mathrm{S}, i j}\left(1+\frac{k_{i j, 1}^{+} E_{j, \mathrm{~T}}}{4 \pi D_{i} r_{\mathrm{c}, j} n_{j}}\right) .
$$

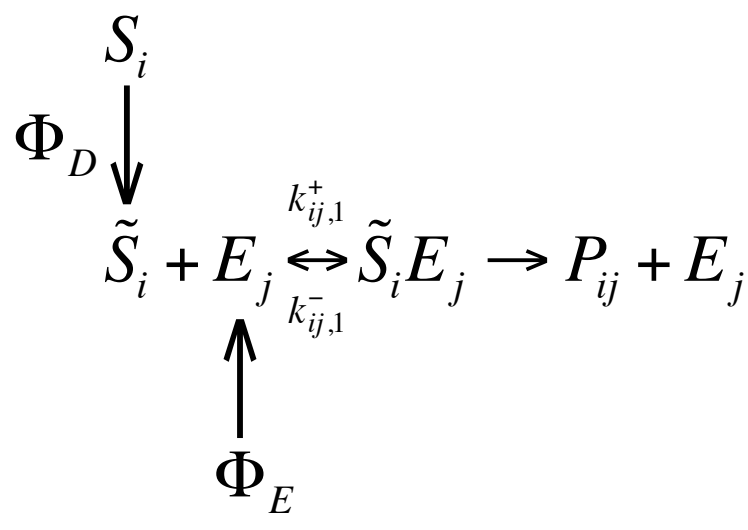

Fig. 2. Diagram of the updated substrate uptake process, which includes diffusive substrate flux (between the external environment and near cell environment) and new enzyme production $\Phi_{\mathrm{E}}$. Here $S_{i}$ is any environmental substrate abundance, $\tilde{S}_{i}$ is the corresponding local (close to the transporter) substrate abundance, and $P_{i j}$ is the assimilated product from the processing of $S_{i}$ by enzyme $E_{j}$.

Under the assumption that $k_{i j, 1}^{-} \ll k_{i j, 2}^{+}$and defining $V_{\max , i j}=k_{i j, 2}^{+} E_{j, \mathrm{~T}}$, one has

$\tilde{K}_{\mathrm{S}, i j}=K_{\mathrm{S}, i j}\left(1+\frac{V_{\mathrm{max}, i j}}{4 \pi D_{i} r_{\mathrm{c}, j} n_{j} K_{\mathrm{S}, i j}}\right)$,

which extends the modified MM kinetics derived for a single enzyme single substrate system (Bonachela et al., 2011) to an enzyme-substrate network of arbitrary size.

Equation (29) implies that if a cell increases its volumetric transporter density $\left(E_{j, \mathrm{~T}} / n_{j}\right.$; transporters per cell), it decreases its substrate affinity. However, considering $E_{j, \mathrm{~T}}=$ $n_{j} \psi_{j} 4 \pi r_{\mathrm{c}, j}^{2}$, if a cell $j$ decreases its volumetric size while keeping the same area-based transporter density $\psi_{j}$ (transporters $\mathrm{m}^{-2}$ ), it can increase its substrate affinity. Further, by substitution of Eq. (28) or Eq. (29) into Eq. (13), one obtains a new representation of the moisture effect on organic matter decomposition (through diffusivity $D_{j}$ and aqueous substrate concentration $S_{i}$ ) that is more mechanistic than the usually applied simple multiplier factors (e.g., Andren and Paustian, 1987; Rodrigo et al., 1997; Bauer et al., 2008; Parton et al., 1988).

\subsection{Evaluation of the ECA kinetics and the classical MM kinetics}

We focus our evaluation on the efficacy of the ECA (Eq. 13) and the MM kinetics (Appendix C) in approximating predictions by the EC kinetics, and leave the analysis of the impact of the EC and ECA kinetics on trait-based modeling (Eq. 28) for future studies. In these comparisons, we used the EC kinetics as a baseline to predict the enzyme-substrate complexes involved in a reaction network with arbitrary number of enzymes and substrates. We implemented the EC kinetics with the analytical equilibrium iteration (AEI; Jacobson, 
1999) and then compared its predictions to those from the classical MM kinetics and the ECA kinetics for different network configurations. We conducted the evaluation with three groups of experiments: (E1) random sampling; (E2) applications to simple microbial models of different complexities; and (E3) simulating litter decomposition with a different carbon-only model. We remark that in all our evaluations all the substrate kinetics used the same number of parameters; therefore, when one formulation is found to perform worse than others, it is inferior in our evaluation framework.

In the first group of experiments (E1; random sampling), we tested the hypothesis that our ECA kinetics is more accurate than the MM kinetics for arbitrary consumer-substrate networks. Specifically, we randomly generated substrate affinity parameters using an exponential distribution over the relative range $1-10^{4}\left(\mathrm{~mol} \mathrm{~m}^{-3}\right)$, which is sufficiently wide to represent the range of microorganisms in the natural environment (e.g., Wang et al., 2012). The enzymes and substrate concentrations were then generated from the least informative uniform distribution $U[0,1]$. We performed 9 scenarios using combinations of three substrate: enzyme (SE) ratios $(10,1$, and 0.01$)$ and three network sizes (60 substrates and one enzyme, 10 substrates and 60 enzymes, and 20 substrates and 20 enzymes). Each scenario has 10 random replicates, resulting in a total of $9 \times 10=90$ evaluations. We normalized the variance of the EC solution for each replicate of the 9 scenarios, and summarized the results using the Taylor diagram (Taylor, 2001), which simultaneously presents the correlation coefficient and root mean square error between the baseline EC solution and solutions using MM or ECA kinetics. Since the equilibrium reaction Eq. (7) is symmetric to represented substrates and enzymes, the 9 scenarios effectively represent 18 different enzyme-substrate networks (e.g., 10 substrates and 60 enzymes is equivalent to 60 substrates and 10 enzymes). We remark that the high enzyme : substrate ratio may not be ecologically significant for modeling litter decomposition such as E3, but it is important to be investigated given our EC and ECA approaches are also applicable for problems such as predator-prey systems, where moderate to high ratio of predator to prey (analogously to that between enzyme and substrate) can easily occur.

In the second group of experiments (E2; simple microbial models of different complexities), we used the following generic model structure to illustratively evaluate the impact of different substrate kinetics on microbial system dynamics:

$$
\begin{aligned}
\frac{\mathrm{d} S_{i}}{\mathrm{~d} t} & =-\sum_{j=1}^{j=J} k_{i j, 2}^{+} C_{i j}, \quad i=1, \ldots, I \\
\frac{\mathrm{d} B_{j}}{\mathrm{~d} t} & =\sum_{i=1}^{i=I} \mu_{i j} k_{i j, 2}^{+} C_{i j}-\gamma_{j} B_{j}, \quad j=1, \ldots, J,
\end{aligned}
$$

where $\mu_{i j}$ (unitless) is the biomass yield rate of microbe $B_{j}$ $\left(\mathrm{mg} \mathrm{C} \mathrm{dm}{ }^{-3}\right)$ from feeding on substrate $S_{i}$, and $\gamma_{j}\left(\right.$ day $\left.^{-1}\right)$ is respiration rate, which is defined accordingly (in the captions of the relevant parameter tables) for different models. We computed $C_{i j}$ using EC kinetics, MM kinetics (Appendix C), and ECA kinetics (Eq. 13) and evaluated the ability of the two analytical approximations to reproduce the temporal dynamics simulated by the EC kinetics. We considered four microbial models of different complexities (Tables 1, 2, and 3; note the fourth model assigned different units to the variables compared to the other three models in order to use the parameters from Moorhead and Sinsabaugh (2006). We note that using the parameters from Moorhead and Sinsabaugh (2006) is simply a choice of convenience, but it is sufficient for a qualitative assessment of the predicted differences between our ECA or EC-based models and the MM model): (i) three substrates and one microbe (S3B1); (ii) three substrates, one microbe, and one mineral surface (S3B1M1); (iii) one substrate and five microbes (S1B5); and (iv) three microbes and three substrates (S3B3). For the three models with three substrates (S3B1, S3B1M1, and S3B3), we related the substrates to water-soluble carbon, cellulose, and lignin, respectively. Since the results from (E2) are applicable to other similar problems, we labeled the three substrates as $S_{1}, S_{2}$, and $S_{3}$. For model S1B5, we ran the model with different kinetics using 20 randomly generated parameter sets, and evaluated their performance by the relative model error:

$$
\operatorname{err}(t)=\frac{3}{N} \sum_{i=1}^{i=N}\left|\frac{y_{i, \mathrm{EC}}(t)-y_{i, \mathrm{app}}(t)}{y_{i, \mathrm{EC}}(t)+y_{i, \mathrm{MM}}(t)+y_{i, \mathrm{ECA}}(t)}\right|,
$$

where $N=6$, the number of model state variables, and app refers to MM or ECA. The above metric avoids division by zero as long as the model difference is non-zero.

For all models (including S1B5), we specified the relevant parameter values randomly, but kept their nominal values in the ranges documented in the literature (for microbial parameters, see Li et al, 1992; Allison et al., 2010; Wang et al., 2012; for mineral adsorption parameters, see Mayes et al., 2012). As an extra comparison, we also included the multicomponent Langmuir isotherm (i.e., Eq. 21, which we notate as ECA-ML) to compute the substrate uptake in models S3B1, S3B1M1, and S3B3. Since ECA-ML can be derived based on SQSSA and it assumes enzyme concentrations are much lower than the substrate concentrations, comparing its performance with that of ECA and EC will reveal the advantage of tQSSA in representing networks with high enzyme concentrations.

We assumed all microbial transporters are generic (so that they can capture all substrates that the microbe can process) and are uniformly distributed over the microbe's cell surface. The total transporter abundance of a given microbe is scaled to the microbial biomass with a constant $z$, which is set to 0.05 , a number that falls in the middle of values applied in other studies (Berg and Purcell, 1977; Maggi and Riley, 2009). We used these experiments to test two hypotheses: (i) the ECA kinetics is more robust than the MM kinetics in 
Table 1. Parameter values for microbial models S3B1 and S3B1M1. The parameter vectors are presented in the form $\left(K_{\mathrm{S}, i j}, k_{i j, 2}^{+}, \mu_{i j}\right)$, whose units are, respectively, $\mathrm{mg} \mathrm{Cdm}^{-3}, \mathrm{~d}^{-1}$, and none. The initial microbial biomass is defined in the parentheses after $B_{1}$, whose unit is $\mathrm{mg} \mathrm{Cdm}^{-3}$. The mineral surface is characterized with the Langmuir dissociation parameter (equivalently $K_{\mathrm{S}, i j}$ ) and the maximum adsorption capacity (in the parentheses following $M_{1}$ ), whose units are, respectively, $\mathrm{mg} \mathrm{C} \mathrm{dm}^{-3}$ and $\mathrm{mg} \mathrm{C} \mathrm{dm}^{-3}$. For both models, we used a microbial respiration rate $0.03 \mathrm{~d}^{-1}$. The microbial parameters were randomly specified based on prior knowledge from Wang et al. (2012), and the mineral surface parameters were specified for Alfisol based on Mayes et al. (2012).

\begin{tabular}{llll}
\hline$S_{1}(30)$ & $S_{2}(100)$ & $S_{3}(90)$ & \\
\hline$B_{1}(0.1)$ & $(1,48,0.5)$ & $(10,48,0.3)$ & $(50,48,0.1)$ \\
$M_{1}(1094)$ & $(21.2,0,0)$ & $(21.2,0,0)$ & $(21.2,0,0)$ \\
\hline
\end{tabular}

Table 2. Parameter ranges for microbial model S1B5. The parameter vectors are presented in the form $\left(K_{\mathrm{S}, i j}, k_{i j, 2}^{+}, \mu_{i j}\right)$, whose units are, respectively, $\mathrm{mg} \mathrm{Cdm}{ }^{-3}, \mathrm{~d}^{-1}$, and none. Numbers in the parentheses following the state variables are their initial values, whose units are $\mathrm{mg} \mathrm{C} \mathrm{dm}^{-3}$. All five microbes used a respiration rate $0.005 \mathrm{~d}^{-1}$. The maximum and minimum parameter values were specified based on Wang et al. (2012).

\begin{tabular}{lll}
\hline & \multicolumn{2}{c}{$S_{1}(300)$} \\
\cline { 2 - 3 } & $\begin{array}{l}\text { Minimum } \\
\text { values }\end{array}$ & $\begin{array}{l}\text { Maximum } \\
\text { values }\end{array}$ \\
\hline$B_{1}(1)$ & $(1,1,0.4)$ & $(100,10,0.4)$ \\
$B_{2}(1)$ & $(1,1,0.4)$ & $(100,10,0.4)$ \\
$B_{3}(1)$ & $(1,1,0.4)$ & $(100,10,0.4)$ \\
$B_{4}(1)$ & $(1,1,0.4)$ & $(100,10,0.4)$ \\
$B_{5}(1)$ & $(1,1,0.4)$ & $(100,10,0.4)$ \\
\hline
\end{tabular}

approximating the EC solution; and (ii) only the ECA kinetics is analytically tractable and sufficiently accurate to model microbial-mineral surface interactions.

For the third set of experiments (E3; simulating litter decomposition), we tested whether the S3B3 model with different substrate kinetics can be calibrated to simulate the 77-month red pine litter decomposition data of Melillo et al. (1989). We first calibrated model S3B3 with both the ECA and MM kinetics, and analyzed if the calibrated models can reproduce the (i) two-phase evolution of remaining organic matter, (ii) increase of lignocellulose index (LCI) during decomposition, and (iii) reasonable fraction of microbial biomass with respect to the remaining organic matter. We then ran the models with 9 different initial litter chemistries (Table 4) for a qualitative assessment of the extrapolated predictability (based on observational data if available) of the calibration. We were able to obtain some time series data for the Massachusetts (MA) site (Magill et al., 1998), but failed to extract any useful time series data for the Wisconsin (WI)
Table 3. Prior parameters for microbial model S3B3. The parameter vectors are presented in the form $\left(K_{\mathrm{S}, i j}, k_{i j, 2}^{+}, \mu_{i j}\right)$, whose units are, respectively, $\mathrm{gC}_{\mathrm{C}} \mathrm{d}^{-1}$ and none. All values are adapted from Moorhead and Sinsabaugh (2006). All three respiratory coefficients (i.e., $\gamma_{j}, j=1,2,3$ as defined in Eq. (30) are set to $0.03 \mathrm{~d}^{-1}$. Numbers in the parentheses following the state variables are their initial values, whose units are $\mathrm{g} \mathrm{C}$.

\begin{tabular}{llll}
\hline & $S_{1}(448)$ & $S_{2}(431)$ & $S_{3}(121)$ \\
\hline$B_{1}(0.33)$ & $(1,1,0.5)$ & $(100,1,0.3)$ & $(5000,1,0.1)$ \\
$B_{2}(0.33)$ & $(1.0,0.8,0.5)$ & $(10,0.8,0.3)$ & $(1000,0.8,0.1)$ \\
$B_{3}(0.33)$ & $(1.0,0.4,0.5)$ & $(10,0.4,0.3)$ & $(100,0.4,0.1)$ \\
\hline
\end{tabular}

Table 4. Characteristics of initial litter chemistry for the data in litterbag decomposition field studies in Wisconsin (WI) and Massachusetts (MA). The table is organized based on Table 3 in Moorhead and Sinsabaugh (2006), who obtained data from Aber et al. (1984) and Magill et al. (1998). The final LCI is model predicted (see Sect. 3.3.2 for details). We have also extracted time series data from the Magill et al. (1998) study for model assessment (Figs. 15 and $\mathrm{S} 1$ ).

\begin{tabular}{lccccc}
\hline $\begin{array}{l}\text { Litter type, } \\
\text { by site }\end{array}$ & $\begin{array}{c}\text { Labile } \\
(\%)\end{array}$ & $\begin{array}{c}\text { Holocellu- } \\
\text { lose }(\%)\end{array}$ & $\begin{array}{c}\text { Lignin } \\
(\%)\end{array}$ & $\begin{array}{c}\text { Initial } \\
\text { LCI }\end{array}$ & $\begin{array}{c}\text { Final } \\
\text { LCI }\end{array}$ \\
\hline Wisconsin (WI) & & & & & \\
Sugar maple & 44.8 & 43.1 & 12.1 & 0.22 & 0.55 \\
Aspen & 31.1 & 47.5 & 21.4 & 0.31 & 0.56 \\
White oak & 32.4 & 47.4 & 20.2 & 0.30 & 0.56 \\
White pine & 32.8 & 44.7 & 22.5 & 0.33 & 0.59 \\
Red oak & 30.0 & 45.2 & 24.8 & 0.35 & 0.59 \\
\hline Massachusetts (MA) & & & & \\
Red pine & 35.9 & 38.6 & 25.5 & 0.40 & 0.67 \\
Red maple & 47.7 & 35.4 & 16.9 & 0.32 & 0.68 \\
Black oak & 35.0 & 39.6 & 25.4 & 0.39 & 0.66 \\
Yellow birch & 43.4 & 40.3 & 16.3 & 0.29 & 0.62 \\
\hline
\end{tabular}

site (Aber et al., 1984) from the original literature or by contacting the authors. In addition, we noticed the original data in Magill et al. (1998) indicated a rise of lignin during the decomposition for some unexplained reasons (see their Fig. 4). We corrected this by replacing the unreasonable lignin data (i.e., those higher than the initial lignin mass) with the initial lignin mass (see Fig. S1 for details).

We solved all microbial models with the mass positive first order ordinary differential equation integrator (Broekhuizen et al. 2008). This numerical solver deals with stiff and discontinuous differential equations well and always ensures mass balance as long as the elemental stoichiometry is properly formulated in the model. We ran all models half hourly, a time step that was selected through trial and error by evaluating the differences of the predictions when using different model time steps. For experiment E2, the total runtime for model S3B1, S3B1M1, and S1B5 were set to 50 days, while 
Table 5. Best-fit parameters for model S3B3-ECA by optimizing the simulation outputs to the 77-month red pine litter decomposition experiment data in Melillo et al. (1989). The parameter vectors are presented in the form $\left(K_{\mathrm{S}, i j}, k_{i j, 2}^{+}, \mu_{i j}\right)$, whose units are, respectively, $\mathrm{g} \mathrm{C}, \mathrm{d}^{-1}$, and none. The respiratory coefficients (i.e., $\gamma_{j}, j=1,2,3$ as defined in Eq. (31) of the three microbes are, respectively, set to $0.01,005$, and $0.001 \mathrm{~d}^{-1}$. Numbers in the parentheses following the state variables are their initial values, whose units are $\mathrm{g} C$. In doing the calibration, we assumed (i) $K_{\mathrm{S}, 1 j}, j=1,2,3$ are same for all three microbes; (ii) $K_{\mathrm{S}, 22}=K_{\mathrm{S}, 23}$; (iii) for microbe $B_{j}, k_{i j, 2}^{+}, i=1,2,3$ are same for all three substrates. By further fixing $\mu_{i j}$ to the values in the parentheses, we effectively had a total 12 parameters in the calibration.

\begin{tabular}{llll}
\hline & $S_{1}(359)$ & $S_{2}(386)$ & $S_{3}(255)$ \\
\hline$B_{1}(4.94)$ & $(2.22,0.6027,0.5)$ & $(96.4,0.6027,0.3)$ & $(283.8,0.6027,0.1)$ \\
$B_{2}(4.22)$ & $(2.22,0.3605,0.5)$ & $(185.2,0.3605,0.3)$ & $(5216.1,0.3605,0.1)$ \\
$B_{3}(2.42)$ & $(2.22,0.2061,0.5)$ & $(185.2,0.2061,0.3)$ & $(219.5,0.2061,0.1)$ \\
\hline
\end{tabular}

that for model S3B3 runtime was 1500 days. All models in experiment E3 were run for the length of the observations (80 months).

Bayesian inference based calibrations for experiment E3 were performed to invert the relevant parameters (see caption of Table 5 for descriptions) of the substrate uptake kinetics from fitting the model (e.g., S3B3-ECA) output to the time series data of the remaining litter mass and lignocellulose index (LCI) from Melillo et al. (1989). We implemented the Bayesian inference using the MCMC algorithm DREAM (Vrugt et al., 2008). A uniform prior was used for all the parameters, with the cost function (or the negative loglikelihood function) defined by

$$
\begin{aligned}
J_{\mathrm{cost}} & =\left(8 \sigma_{\mathrm{LCI}}\right)^{-1} \sum_{k=1}^{k=8}\left|\mathrm{LCI}_{k}-\mathrm{LCI}_{\mathrm{ECA}, k}\right| \\
& +\left(17 \sigma_{\mathrm{Mass}}\right)^{-1} \sum_{k=1}^{k=17}\left|r_{\mathrm{Mass}, k}-r_{\text {Mass }, \mathrm{ECA}, k}\right|
\end{aligned}
$$

where $\mathrm{LCI}_{k}$ is the $k$ th observation of lignocellulose index (of which there are 8 data points) and $r_{\text {Mass, } k}$ is the $k$ th observation of relative remaining organic matter biomass (microbe plus litter; of which there are 17 data points). Both $\sigma_{\text {LCI }}$ and $\sigma_{\text {Mass }}$ are set to 0.01 . For the posterior parameters, the set that minimizes $J_{\text {cost }}$ is defined as the modal (i.e., best fitting) parameter.

\section{Results and Discussion}

\subsection{E1: computing enzyme-substrate complexes for large networks}

For the first set of experiments, we found that ECA kinetics performed better or as well as MM kinetics in approximating the baseline EC solutions. When the substrate to enzyme ratio was high (i.e., enzyme availability is limiting decomposition; green symbols in Fig. 3), the ECA solutions agreed with the EC solutions with correlation coefficients higher than 0.95 and root mean square errors less than 0.5 standard deviations $(\sigma)$, except for 2 (out of 10) random replicates for case $S(60) E(1) r(10)$ (i.e., 60 substrates, 1 enzyme, and a substrate to enzyme abundance ratio of 10; similar nomenclature is used henceforth) and 3 (out of 10) replicates for case $S(20) E(20) r(10)$, whose correlation coefficients were still good $(\sim 0.80)$ and the corresponding root mean square errors were between $0.5 \sigma$ and $1.5 \sigma$.

MM kinetics also achieved good accuracy in approximating the EC solution with correlation coefficients between 0.75 and 0.97 , but in general higher root mean square errors. For case $S(10) E(60) r(10)$, MM kinetics only achieved a correlation coefficient of 0.80 and root mean square errors greater than $0.5 \sigma$, whereas ECA kinetics achieved correlation coefficients of $\sim 0.99$ and root mean square errors smaller than $0.3 \sigma$. However, the worst approximations (in terms of root mean square error) by the MM kinetics (i.e., two replicates, green diamond symbols, for $S(60) E(1) r(10))$ were better than those from the ECA kinetics (for these two poorly simulated replicates).

Similarly contrasting results were found for the cases when the substrate to enzyme ratio was one (purple symbols in Fig. 3): (i) the best approximation by the ECA kinetics was better than that using the MM kinetics and (ii) the MM kinetics resulted in 2 outliers for the case $S(20) E(20) r(1)$ with root mean square errors greater than $2 \sigma$ and correlation coefficients less than 0.90. ECA kinetics also produced 4 random replicates (2 for case $S(10) E(60) r(1)$ and 2 for case $S(20) E(20) r(1))$ that had correlation coefficients close to 0.8 , but the root mean square error was less than $1.5 \sigma$.

When substrate was limiting (blue symbols), both the ECA and MM kinetics produced poor approximations (with more outliers) compared to the EC solutions. Both approaches produced 4 outliers ( 2 for case $S(10) E(60) r(0.01)$ and 2 for case $S(20) E(20) r(0.01))$ with correlation coefficients between 0.70 and 0.80 and root mean square errors greater than $1 \sigma$. The worst results (the 2 replicates for $S(20) E(20) r(0.01)$ ) by MM kinetics were again worse than those by ECA kinetics.

When all sampling experiments were normalized together (cyan circles), we found the ECA kinetics better approximated the baseline EC solution (with similar coefficients of correlation but smaller root mean square errors) than the MM kinetics did. Therefore, we summarize that the ECA 


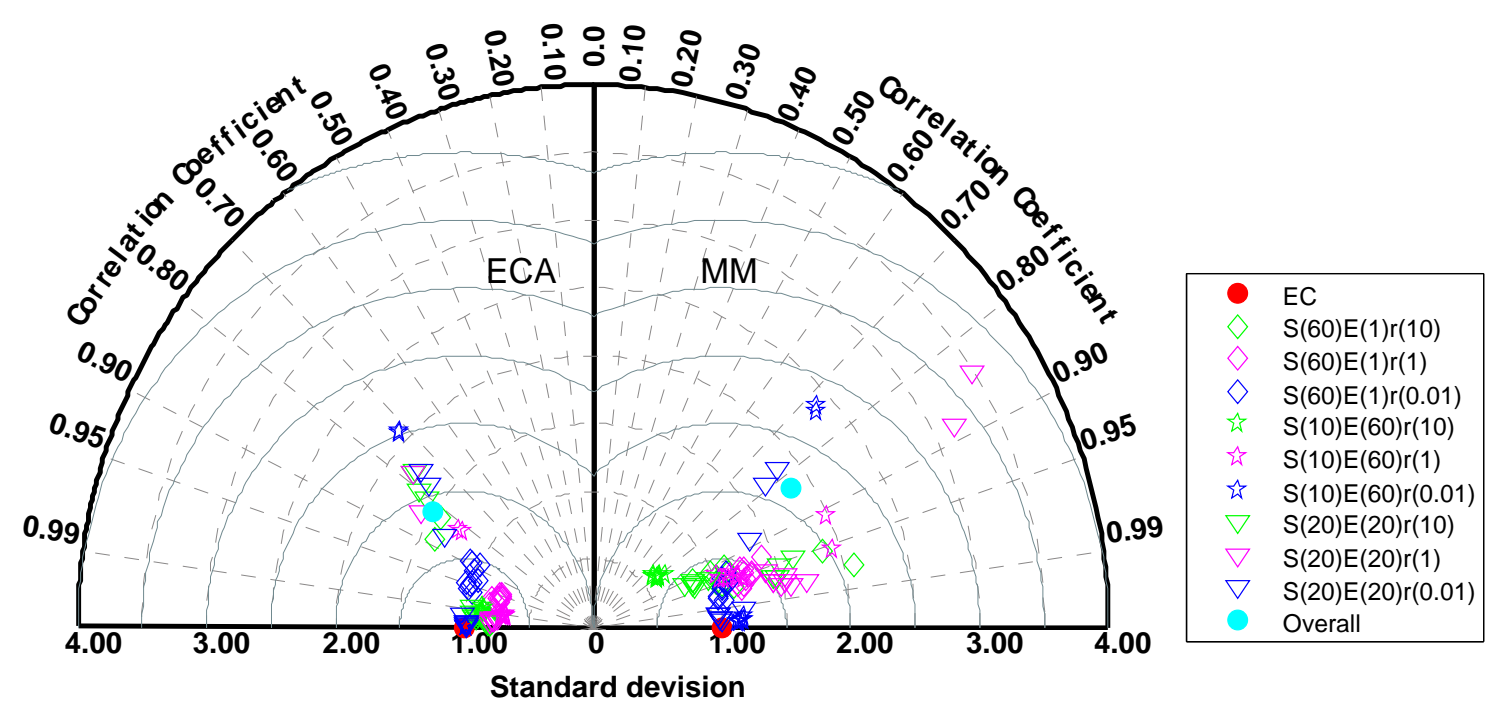

Fig. 3. A Taylor diagram based summary of the random sampling experiment (E1) that compared the ability of the ECA and the MM kinetics to approximate different enzyme-substrate networks simulated by the EC kinetics. Each symbol has 10 random replicates. The values in the parentheses indicate the number of substrates or enzymes. The nomenclature $S(x) E(y) r(z)$ indicate a network of $x$ substrates, $y$ enzymes, and a substrate to enzyme abundance ratio of $z$.

kinetics is superior to the MM kinetics in representing largesize consumer-substrate networks.

\subsection{E2: application to simple microbial models}

We found three (EC, ECA, ECA-ML) of the four different substrate kinetics led to almost identical model predictions for the S3B1 scenario over the 50-day time period (Figs. 4 and 5). The MM predictions deviated from the others slightly. However, the good agreement between the MM kinetics and the other kinetic formulations is serendipitous. The MM kinetics is poor in describing enzyme competition in the presence of multi-substrates, which has been identified in several studies (e.g., Maggi and Riley, 2009; Druhan et al., 2012). We also replicated this behavior with an isotope-modeling example (see Supplement), where it was shown the MM kinetics has very poor predictability for multi-isotopic fractionations (Fig. S3), even though it predicted the bulk substrate and microbial dynamics with acceptable accuracy (Fig. S2).

When mineral surface interactions were further included (in the S3B1 model) to form the S3B1M1 model, we found that the ECA kinetics again predicted very similar time series compared to that from EC kinetics (Figs. 6 and 7) because both ECA and EC are able to consistently represent the substrate competition by microbe and mineral surfaces. However, both the ECA-ML and MM kinetics resulted in predictions substantially different from the EC solution. The ECA-ML predicted a much faster turnover rate of all three substrates because it did not include the inhibitory term due to the presence of consumers (which can be confirmed by comparing Eq. 13 to Eq. 21) and thence resulted in a
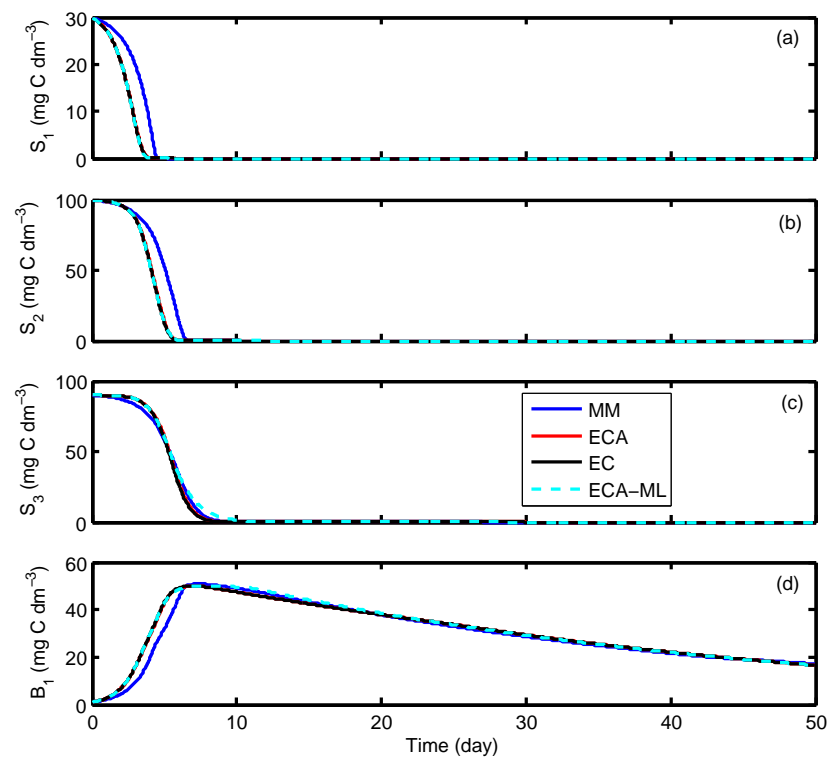

Fig. 4. Time series of the relevant state variables simulated from the applications of the four different substrates uptake kinetics to microbial model S3B1.

weaker substrate adsorption to the mineral surface. Furthermore, throughout the 50-day period, the microbe grew in its biomass and consequently increased its quota to capture substrate, whereas the mineral surface had a fixed quota, which together with the growing microbe resulted in a faster turnover of the three substrates. In contrast, MM kinetics favored more substrate adsorption to the mineral surface 

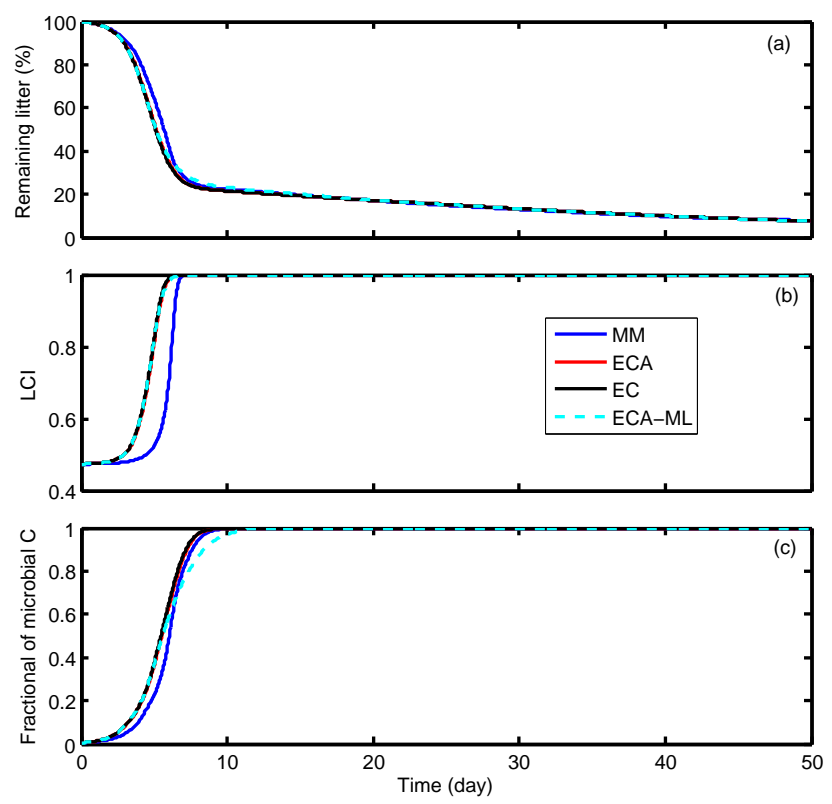

Fig. 5. Time series of state variable ratios simulated from the application of the four different substrates uptake kinetics to microbial model S3B1.

because (by comparing Eq. C1 to Eq. 13) it did not include the nonlinear competitive inhibition on substrate uptake or the inhibition due to the presence of the consumer. In addition, the mineral adsorption sites (counted as adsorption capacity by the state variable $M_{1}$ in Table 1) is much more abundant than microbial transporters, which resulted in a strong limitation on microbial substrate uptake. This substrate limitation (due to mineral surface adsorption) led to a much lower microbial growth, which then led to a greatly underestimated substrate turnover rate (by the MM kinetics). Therefore, the reduction in turnover of the three substrates in presence of mineral surface adsorption leads us to conjecture that mineral adsorption (and consequently protection, which is not considered here but can be incorporated by using approaches such as in Wang et al., 2013) is an important mechanism impacting organic matter degradation with depth in the soil profile. Implementing the ECA or EC kinetics could thus potentially avoid the ad hoc parameterization of soil organic matter (SOM) decomposition rate slowdown with depth, as has been implemented in some vertically resolved SOM models (e.g., Jenkinson and Coleman, 2008; Koven et al., 2013). In accordance with the predicted substrate dynamics, we note that MM kinetics predicted the slowest increase in LCI and fractional microbial C (with respect to total organic $\mathrm{C}$ including both substrates and microbial biomass), while the ECA-ML kinetics predicted the fastest increase (Fig. 7). These findings lead us once again to state that the MM kinetics is qualitatively not appropriate when the problem involves multiple substrates and multiple
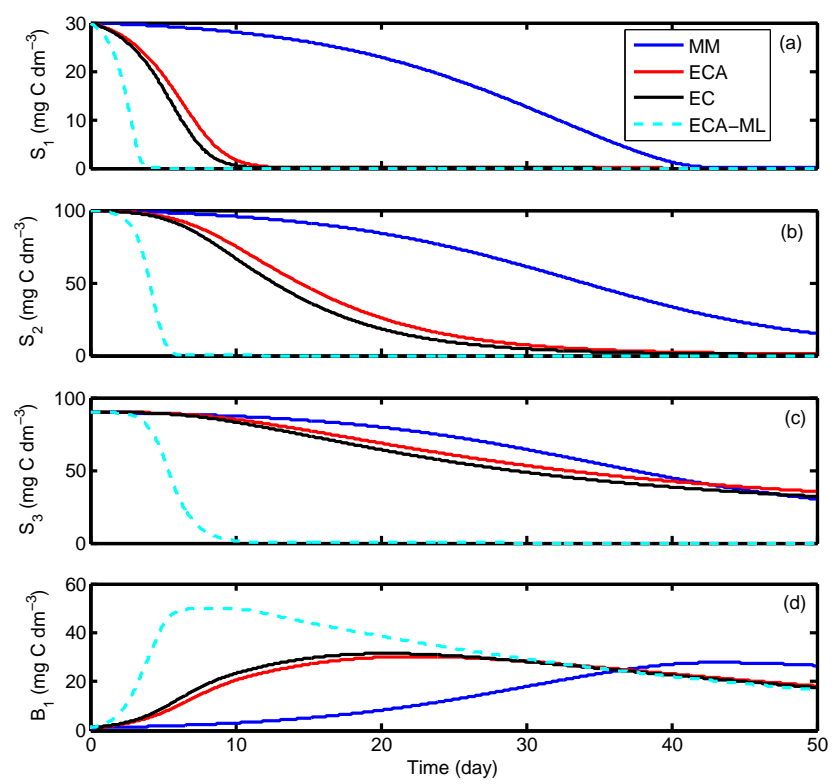

Fig. 6. Time series of the relevant state variables simulated from the applications of the four different substrate uptake kinetics to microbial model S3B1M1.
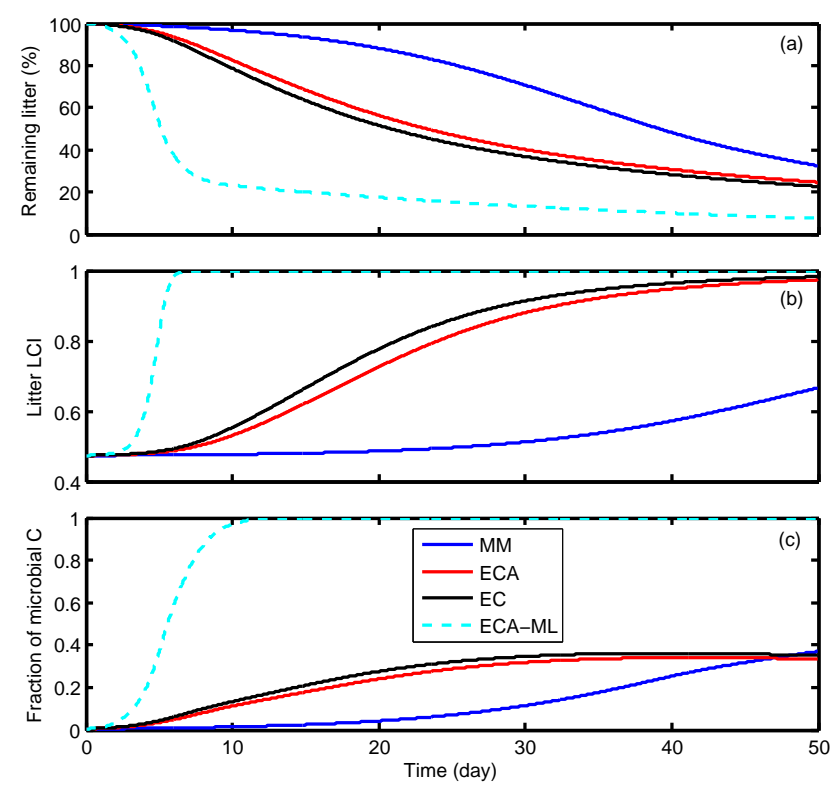

Fig. 7. Time series of state variable ratios simulated from the application of the four different substrates uptake kinetics to microbial model S3B1M1.

consumers. In addition, as we will show in experiment E3, such deficiencies cannot be remedied through calibration.

When five microbes are competing for a single substrate (S1B5), we found the three different substrate kinetics (now ECA-ML kinetics has the same functional form as MM kinetics when there is only one substrate) made equally good predictions (Fig. 8). For the worst case (according to the 

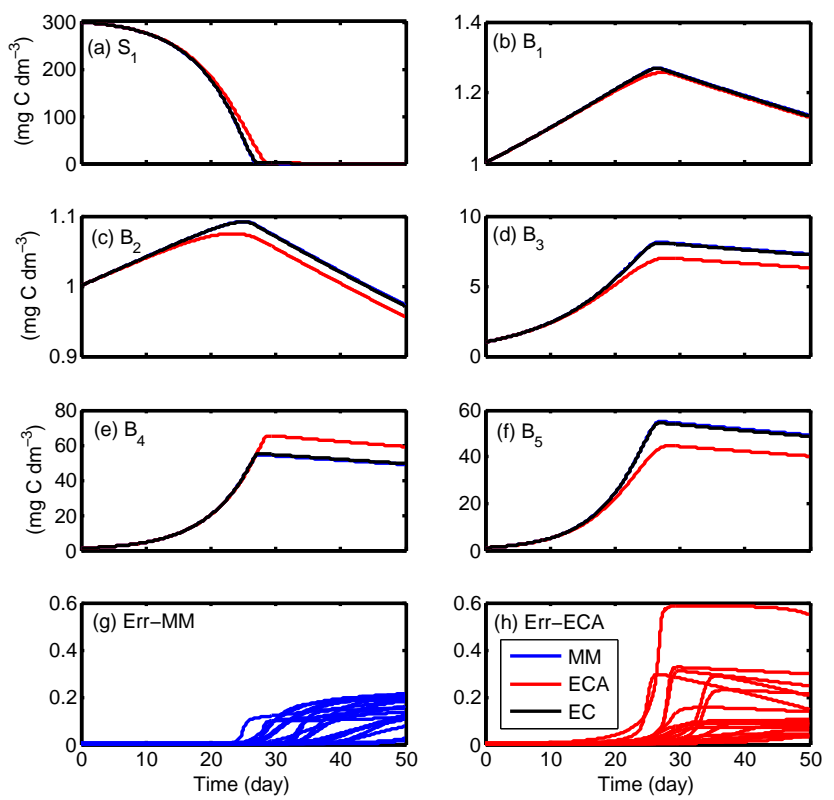

Fig. 8. Comparison of simulations using different substrate kinetics in scenario S1B5: (a-f) are from the simulation that showed the most distinctive differences; (g) and (h) are summaries of the model differences (with respect to the EC results) from the ensemble of 20 random simulations.

metrics defined in Eq. 32) among the 20 runs with randomly generated parameters (see Table 2 for parameters being sampled), the prediction by the MM kinetics fit the EC predictions better than did the ECA kinetics (Fig. 8a-f). When summarized over the 20 runs (Fig. $8 \mathrm{~g}-\mathrm{h}$ ), we found that the MM kinetics is slightly superior for problems that are in the form of many microbes competing for a single substrate. This result is consistent with model result such as that in Bouskill et al. (2012), where the ammonia and nitrite oxidizers have a very weak overlap in substrates. However, if one tries to use isotopic data to improve the parameterization of such models, the MM kinetics should be replaced with the ECA kinetics or the EC kinetics.

For model S3B3, three of the four substrate kinetics (ECA-ML, ECA, and EC) made very similar predictions (see Figs. 9 and 10). The predictions from the MM kinetics were completely different, both qualitatively and quantitatively. The MM kinetics predicted a gradual reduction in LCI (which stabilized at a constant value smaller than the initial value; see Fig. 10b), whereas the other kinetic models predicted a gradual increase in LCI, which stabilized at a greater (than the initial) value. In addition, the MM kinetics predicted a much higher peak fractional total microbial biomass (compared to the total biomass accounting for both litter and microbes) than did the other substrate kinetics (Fig. 10c). We note that ECA-ML, ECA, and EC all predicted similar temporal evolutions of the remaining litter and litter LCI that qualitatively agreed with findings from litterbag
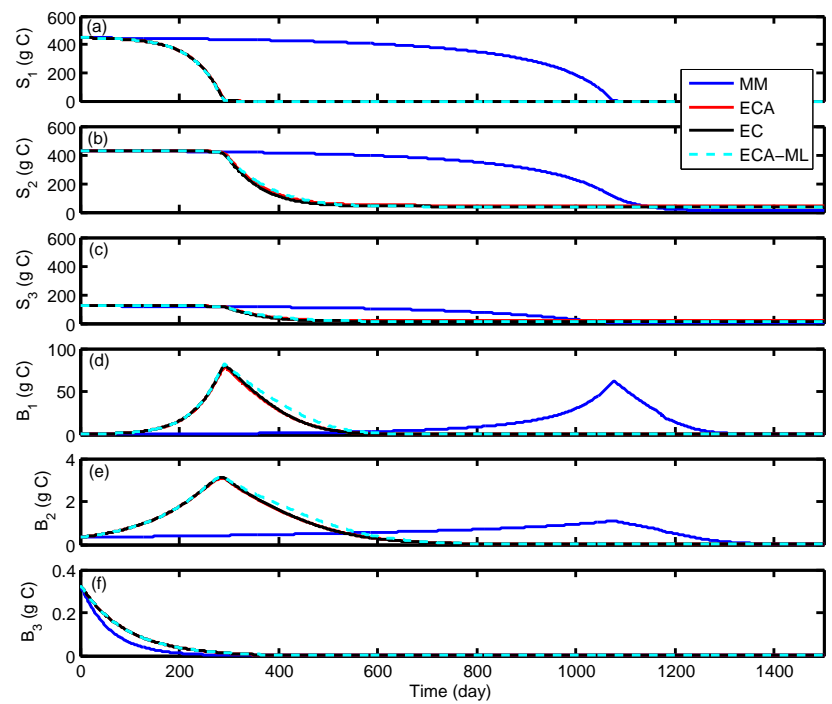

Fig. 9. Time series of relevant state variables simulated from the application of different substrate kinetics to microbial model S3B3.
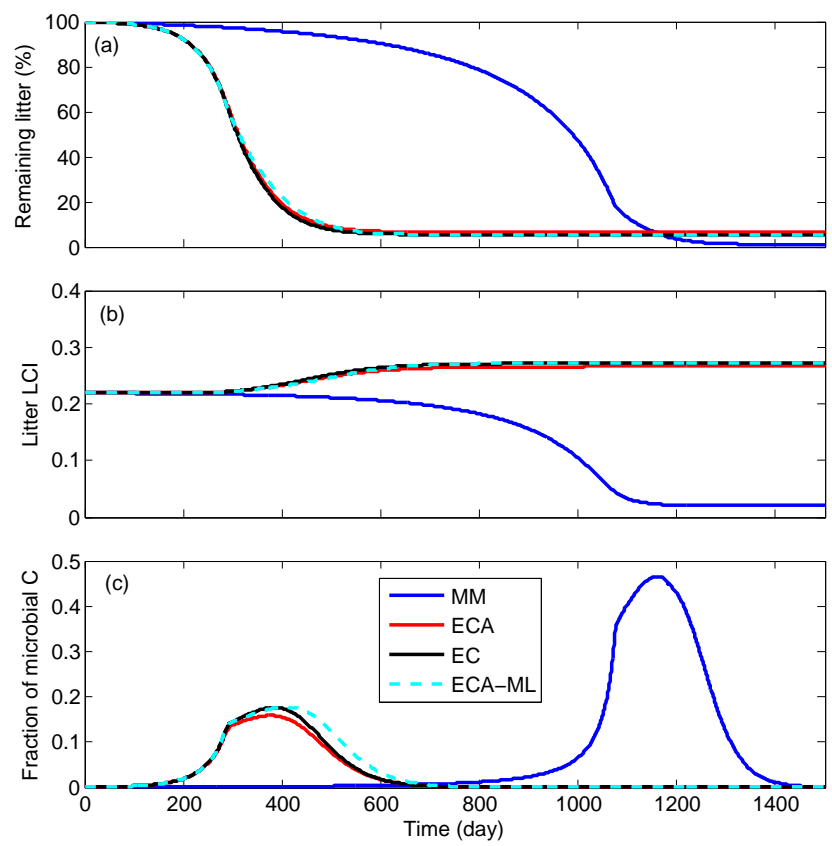

Fig. 10. Time series of state variable ratios simulated from the application of the four different substrates uptake kinetics to microbial model S3B3.

experiments (Fig. 10): (i) the litter decomposition has two distinct phases, where the fist phase is fast and the second phase is much slower and (ii) the LCI increases along with the decomposition and finally stabilizes at a higher value than the initial state (e.g., Melillo et al., 1989; Aber et al., 1990; Magill et al., 1998). This finding leads us to assert that the explicit modeling of nonlinear substrate competition (as formulated in EC, ECA, and ECA-ML) in microbial litter 
decomposition is important to represent measured litter dynamics. Once this nonlinear competition is accounted for, the observed temporal evolution of LCI (and consequently lignin degradation) emerges from the proposed model (EC and ECA). On the other hand, MM kinetics is not structured to account for such nonlinear competition, thus one has to enforce an otherwise unconstrained lignin shielding effect on cellulose degradation (though we do not rule out its possible existence) to make the model well behaved (e.g., Moorhead and Sinsabaugh, 2006; Allison, 2012).

\subsection{E3: simulating litter carbon decomposition}

\subsubsection{Calibrating model S3B3 with different substrate kinetics}

After calibrating the S3B3-ECA model (model S3B3 implemented with ECA; same nomenclature are used henceforth) to the 77-month red pine litterbag experiment data, we found the posterior best-fit parameters led to predictions in good agreement with the measured time series of remaining litter and LCI (Fig. 11). The posterior microbial biomass also seemed qualitatively reasonable, which stayed below $15 \%$ of total organic carbon (including both litter and microbial biomass). Observational data indicate the fractional microbial biomass is relatively low, usually within $10 \%$ of the total organic carbon (Ladd et al., 1994; Dilly and Munch, 1996). Therefore, considering the parameterization equifinality due to insufficient observational data to constrain the relevant parameters (e.g., Tang and Zhuang, 2008) and the qualitatively good agreement between posterior simulations and the available data, we conclude that ECA kinetics is a better choice than MM kinetics in our parsimonious framework to represent litter decomposition dynamics.

We also ran the S3B3 model with the ECA-ML and EC kinetics using the same parameters obtained from S3B3-ECA model calibration and obtained almost identical predictions (see red and cyan lines in Fig. 11). As a sensitivity test, we further introduced the temperature effect on substrate uptake (labeled as ECA-T in Figs. 11 and 13) by applying three different Q10 values (whose values are, respectively, 2.7, 1.5, and 1.7 based on Bayesian inversion on top of the default S3B3-ECA model calibration) to the three biomass yield rates. We found the predictions (blue lines in Fig. 11) changed slightly compared to the simulations without accounting for temperature effects. Though the Q10 values are quite uncertain because of data limitations, the result indicates that temperature was not the single mechanism that led to the differences between measurement and posterior model prediction. Other mechanisms such as leaching, nutrient dynamics, and moisture effects should be investigated in future studies to improve the EC and ECA litter decomposition kinetics.

Calibrating the model with the Michaelis-Menten kinetics (S3B3-MM) to the 77-month litterbag data failed to ob-
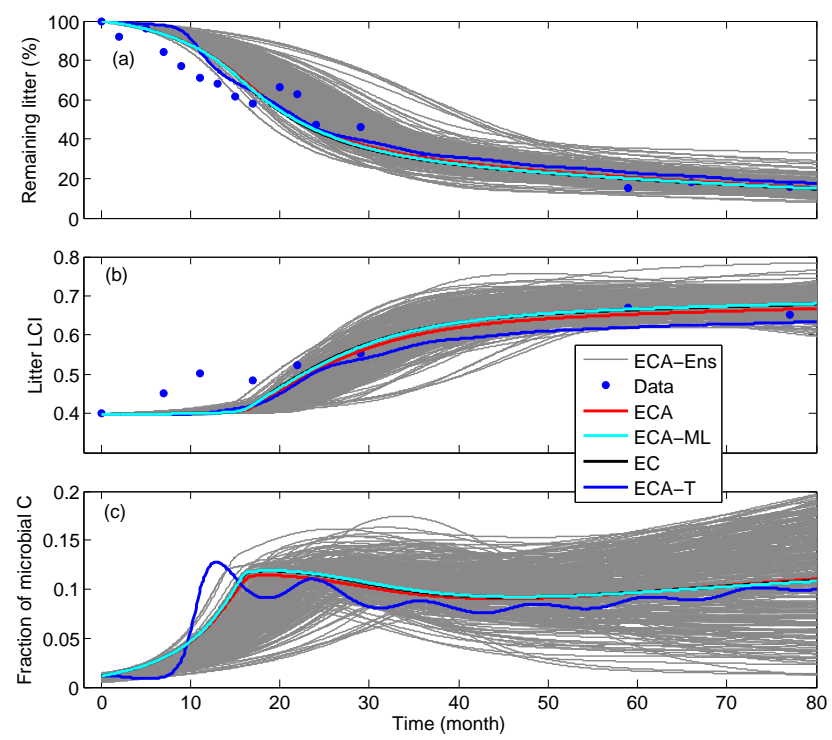

Fig. 11. Posterior simulations from calibrating model S3B3-ECA to the red pine litter decomposition experimental data in Melillo et al. (1989). ECA-Ens indicates the posterior ensemble simulations, and ECA-T indicates the additional temperature impact on top of ECA (i.e., the best fitting posterior simulation). The best-fit kinetic parameters for ECA, EC, ECA-ML, and ECA-T are in Table 5. See text for further details.

tain reasonable posterior predictions of the litter decomposition dynamics (Fig. 12). A few parameter combinations led to qualitatively reasonable predictions of the two-phase evolution of remaining biomass and the increasing, then stabilizing behavior of LCI. Yet the fractional microbial biomass varied wildly. Many parameter combinations predicted the total biomass as microbial-C dominated (almost $100 \%$ ) during the second phase of litter decomposition. We also found the model S3B3-MM is much more sensitive to the parameters than the models implementing ECA-ML, ECA, and EC kinetics. Therefore, we conclude that MM kinetics is not suitable for modeling microbial litter decomposition and SOM dynamics in our more parsimonious framework (than other existing models), since these problems always involve multiple substrates and multiple microbes.

\subsubsection{The interaction between litter chemistry and microbial diversity}

Distinct shifts in microbial community structure were observed in the posterior model predictions for the 77-month litter decomposition experiment (Figs. 13 and S4). While we had no measurements from this experiment to assess whether such predictions are realistic, some other studies (e.g., Keeler et al., 2009; Wickings et al., 2012) indicate such microbial community structure shifts often occur in long-term incubation experiments. For instance, Wickings et al. (2012) observed significant changes in exoenzyme activities and 

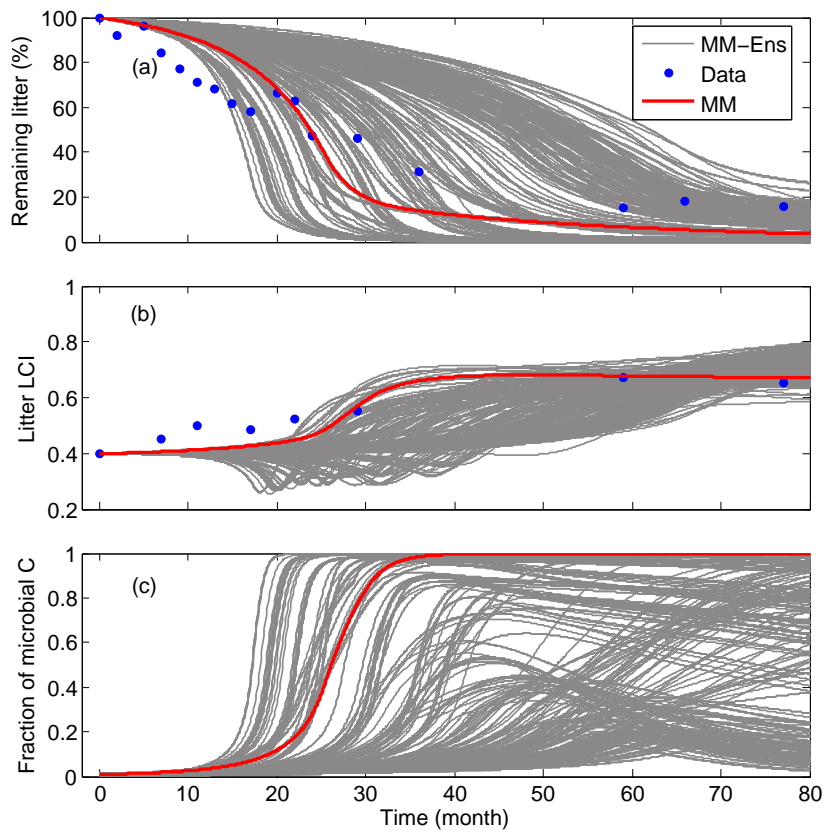

Fig. 12. Posterior S3B3-MM simulations by calibrating the model to the 77-month red pine litterbag experimental data in Melillo et al. (1989). MM-Ens indicates the posterior ensemble simulations. The best-fit posterior simulation is in red, whose corresponding parameters are in Table $\mathrm{S} 2$.

fungal : bacterial ratio in their long-term (730 days) litter decomposition experiment. Considering that fungi often dominate lignin decomposition (Osono, 2007), our predicted dominance of the fungi-like microbe in the second phase of the 77-month decomposition is qualitatively reasonable. Nevertheless, a comprehensive assessment should use a model that has a complete representation of the relevant nutrient dynamics (e.g., $\mathrm{N}$ and phosphorus) and such a model should be compared to detailed observational characterization of litter chemistry and microbial community structure. However, detailed observational characterization of both substrate and microbial community structure is lacking in long-term experiments that cover temporal scales varying from diurnal cycles to multiple years. These types of observations are critical to the development of the types of models discussed here.

Considering each member of the posterior ensemble simulation as a single red pine litter decomposition experiment with a different microbial community, our results (Figs. 11 and 13) indicate that the evolution of litter chemistry is strongly regulated by microbial community structure. In addition, parameterization equifinality (see gray lines in Figs. 11 and 13) indicate different microbial communities will sometimes lead to similar litter chemistry after a relatively long time. The latter is manifested as a weak convergence of litter chemistry in terms of LCI throughout the 77-month period (Fig. 11b; also see the review about measurements in Melillo et al., 1989). Yet we found that the fi-
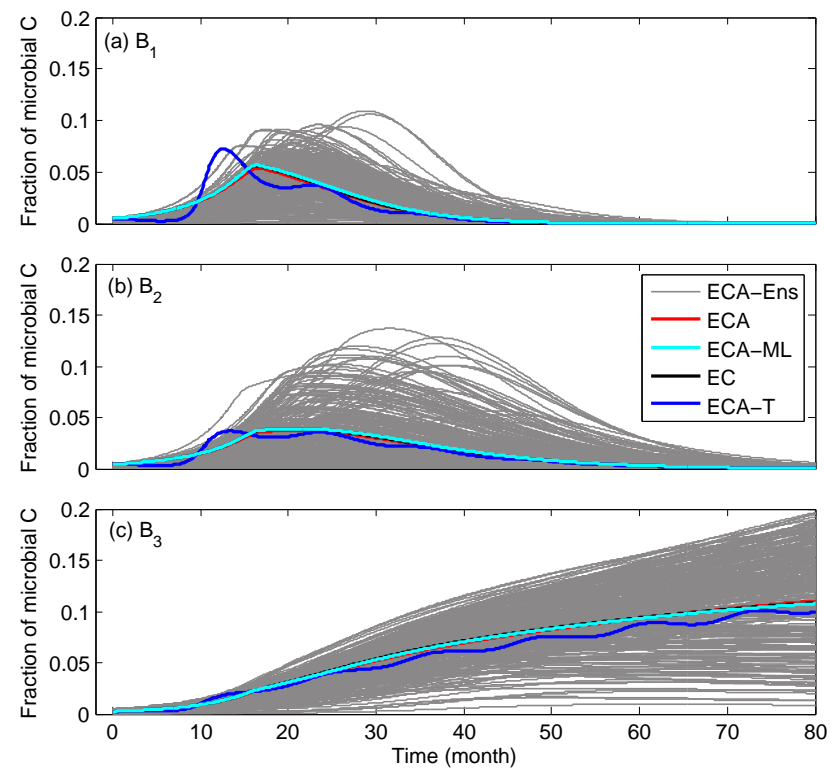

Fig. 13. Simulated time series of microbial abundances from using the best-fit parameters (calibrated with S3B3-ECA) in Table 5. The four models ECA, ECA-ML, EC, and ECA-T used the same kinetic parameters. The ECA-Ens simulations correspond to the ensemble simulations in Fig. 11.

nal, seemingly constant LCI is not a single value but rather a range between 0.6 and 0.8 for the red pine litter being modeled here.

When we applied the model S3B3-ECA using the best-fit parameters (Table 5) from the Bayesian calibration to 9 different litter types (Table 4), the results (Fig. 14) indicated a clear dependence of litter decomposition on initial litter chemistry. The predictions indicate all 9 litters were degraded in two phases, and their LCIs rose asymptotically to different final constant values. Furthermore, the final constant LCI is a function of both its initial value and the microbial community diversity and dynamics. For instance, the red maple started with a medium initial LCI $(0.32)$ but reached a final value of 0.68 , the highest among the 9 litters (Table 4). While we failed to obtain sufficient data to evaluate the 9 predictions, the evaluation of the 4 litter types in the study by Magill et al. (1998) indicated our model predictions were qualitatively reasonable (Fig. 15). We also applied the Michaelis-Menten kinetics model (S3B3-MM) with its best-fit parameter (Table S2) to the 9 litter types; its prediction was again poor (see Fig. S5).

Therefore, we summarize that litter decomposition is coregulated by both the initial litter chemistry and microbial community structure and dynamics. Our prediction supports the conclusion drawn in Wickings et al. (2012) and challenges the assumptions of constant final LCI and constant microbial community structure in many existing biogeochemical models, e.g., the GDM model (Moorhead and Sinsabaugh, 2006), which used a constant final LCI, and 


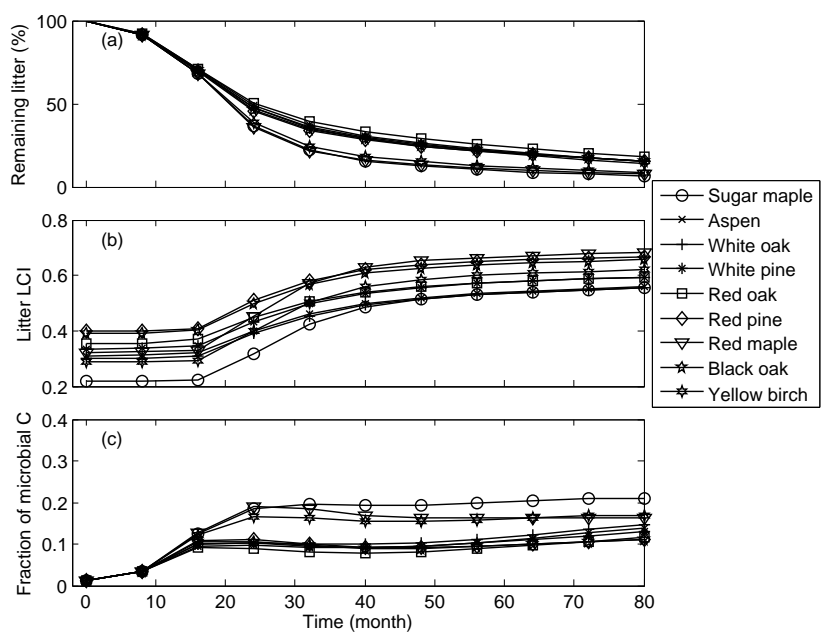

Fig. 14. Model (S3B3-ECA) predicted temporal evolution of litter decomposition dynamics for the 9 different litters in Table 4 . The used parameters are in Table 5.
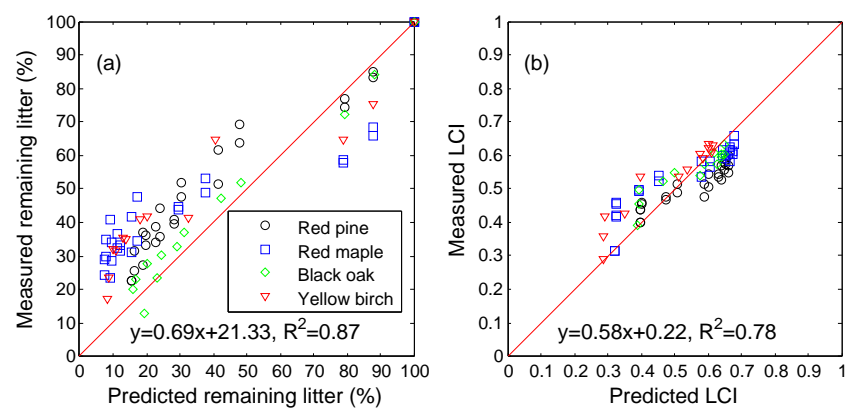

Fig. 15. Evaluation of model (S3B3-ECA) prediction using Magill et al. (1998) litterbag experiment data: (a) remaining litter biomass and (b) litter lignocellulose index (LCI). The original and corrected lignin data are in Fig. S1.

models such as TEM (McGuire et al., 1997), CENTURY (Parton et al., 1988), and Roth-C (Jenkinson and Coleman, 2008), which implicitly assumed the relevant microbial community structures are constant.

\subsubsection{The emergent lignin decomposition dynamics}

Lignin dynamics play a critical role in litter decomposition (Berg et al., 1982; Melillo et al. 1982; Machinet et al., 2011). The physically reasonable prediction by model S3B3-ECA provided us with some new insights on lignin decomposition. We found (Fig. 16) that lignin decomposition does not follow the conceptual model proposed by Berg and Staaf (1980), which states that no lignin will be degraded until it reaches a threshold concentration (with respect to the total litter). Rather, our predictions support the conceptual model of Klotzbucher et al. (2011), which states that lignin decomposition depends on the availability of easily degradable labile carbon. However, our results add further insights that,

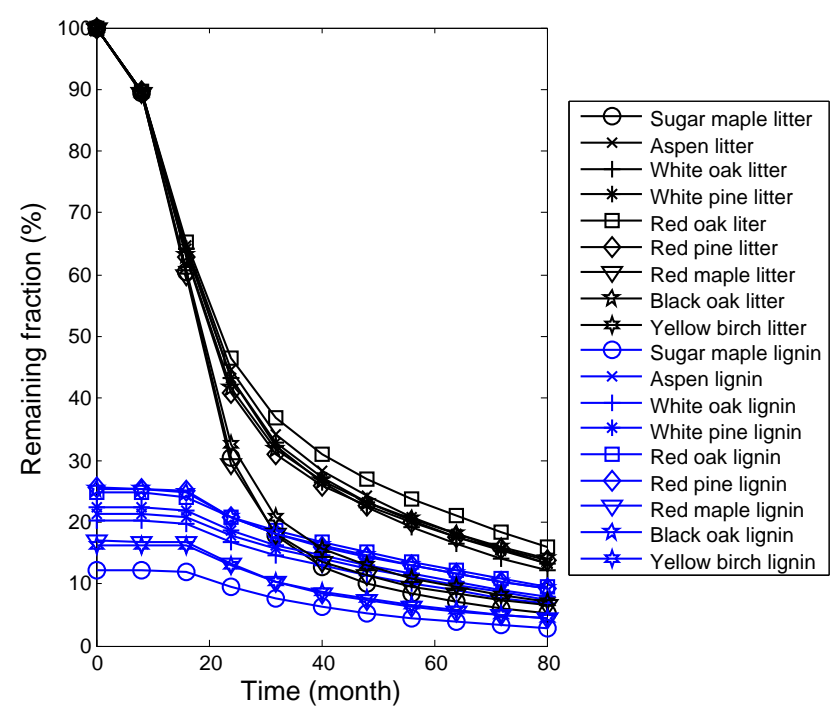

Fig. 16. Model (S3B3-ECA) predicted temporal patterns of total litter and lignin degradation for the 9 different litter types.

besides litter chemistry, degradation is also regulated by microbial community structure. When different groups of microbes are degrading the same type of litter, the litter chemistry could evolve differently (e.g., Fig. 11). We note that lignin decomposition is also regulated by nutrient dynamics such as the nitrogen availability (Herman et al., 2008), which will be explored in our follow up studies.

\subsection{Potential improvements to the EC and ECA substrate kinetics for modeling microbial systems}

Substrate uptake is a process regulated by many biotic and abiotic factors. For soil microbial systems, relevant abiotic factors are soil moisture, temperature, mineralogy, aggregation, and redox potentials (e.g., Davidson and Janssens, 2006). As we explained in Sect. 2.1, EC kinetics allow a direct and consistent description of these abiotic processes using the existing knowledge of reactive transport modeling (Jennings et al., 1982; Jin and Bethke, 2007). Incorporating these factors within the ECA kinetics is more difficult. However, besides the diffusion limitation (which partly accounts for the soil moisture effect as we discussed in Sect. 2.1), accounting for the temperature effect in ECA kinetics is straightforward by recognizing that all parameters in Eq. (4) are temperature dependent. For instance, by using Eyring's transition state theory (Eyring, 1935a, b), it can be shown that $K_{\mathrm{S}, i j} \propto \exp (-\Delta H / R T)$, where $\Delta H\left(\mathrm{~J} \mathrm{~mol}^{-1}\right)$ is an activation energy that should be deducible from measurements (as was done in Davidson et al. (2012), though there they assumed $K_{\mathrm{S}, i j}$ was a linear function of temperature). Determining the activation energies of $k_{i j, 1}^{+}, k_{i j, 1}^{-}$, and $k_{i j, 2}^{+}$could be challenging, but we note that it has been done for inorganic chemistry kinetics (e.g., Bonner et al., 1935). By 
combining these ideas with the theory of half reactions (e.g., McCarty, 2007) and assuming other abiotic factors such as soil aggregation and thermal degradation can be represented by chemical kinetics, one could (and we hope to in future work) construct a thermodynamically-based model of microbial organic matter decomposition.

Other biological factors, such as exoenzyme abundance and microbial transporters, affect the substrate uptake process indirectly by changing the abundance of consumers in the consumer-substrate network. Developing mechanistic representations of these factors is an important area of study (Allison, 2012; Kooijman and Troost, 2007) that we will also address in follow-on studies with the EC and ECA kinetics based model.

\subsection{Potential applications to different network systems}

Because EC kinetics only relies on the premise that the equilibration of the consumer-substrate complexes (between their formation and degradation) is much faster than other metabolic processes, it can in principle be applied to arbitrary food web structures (e.g., Lindeman, 1942) and proteinprotein interaction networks (Ciliberto et al., 2007). We note, however, that a model implemented with the EC kinetics may become computationally expensive as the problem size increases. For such cases, proper numerical preconditioning becomes necessary.

Compared to EC kinetics, the approximate ECA kinetics is applicable to a smaller scope of problems, constrained by the condition that any element in the network be either a substrate or consumer, but not both. Still, the ECA kinetics is much more general than other existing formulations used for predator-prey systems (Murdoch, 1973; Koen-Alonso, 2007) and is computationally very efficient. For proteinprotein interaction networks, one feasible application example is the phosphorylation-dephosphorylation cycle analyzed by Goldbeter and Koshland (1981), which lends itself to be solved by ECA kinetics under the tQSSA (compare their Eqs. 1 and 2 with the form of Eq. 4).

\section{Conclusions}

In this study, we proposed that an equilibrium chemistry (EC) formulation could be used to predict the dynamics of consumer-substrate complexes involved in an arbitrary consumer-substrate network. When the given consumersubstrate network satisfies the condition that any element of the network is either consumer or substrate but not both, we obtained a first-order accurate approximation to EC (termed ECA). Both the EC and ECA kinetics allow a simultaneous and consistent treatment of biotic and abiotic interactions in microbial systems (though the ECA kinetics is more limited), which cannot be achieved with the classical MM kinetics or with other existing MM kinetics based extensions. With a few examples, we demonstrated that if a network involves multiple substrates and consumers, direct application of the classical MM kinetics is inaccurate. We further showed a carbon-only model implemented with the ECA kinetics predicted litter decomposition dynamics reasonably. These predictions indicated that litter decomposition is coregulated by litter chemistry and microbial community structure and dynamics. We hope our results can help develop a benchmark model for microbially-mediated organic matter decomposition in terrestrial and other ecosystems and stimulate applications in other fields involving consumer-substrate networks.

\section{Appendix A}

\section{Derivation of Eq. (13)}

In this section we present the derivation of Eq. (13). From the mass balance constraint to substrate $S_{i}$ (Eq. 10), one has

$$
S_{i}=\frac{S_{i, \mathrm{~T}}}{1+\sum_{k=1}^{k=J} \frac{E_{k}}{K_{\mathrm{S}, i k}}}
$$

Similarly (from Eq. 12), one has

$$
E_{j}=\frac{E_{i, \mathrm{~T}}}{1+\sum_{k=1}^{k=I} \frac{S_{k}}{K_{\mathrm{S}, k j}}}
$$

Substituting Eqs. (A1) and (A2) into Eq. (6), one obtains

$$
C_{i j}=\frac{S_{i, \mathrm{~T}} E_{j, \mathrm{~T}}}{K_{\mathrm{S}, i j}\left(1+\sum_{k=1}^{k=J} \frac{E_{k}}{K_{\mathrm{S}, i k}}\right)\left(1+\sum_{k=1}^{k=I} \frac{S_{k}}{K_{\mathrm{S}, k j}}\right)} .
$$

We then apply the perturbation theory (e.g., Bender and Orzag, 1999; Tang et al., 2007) to Eq. (A3), in which we assume

$C_{i j}=\varepsilon C_{i j, 1}+\varepsilon^{2} C_{i j, 2}+\ldots$

$E_{j}=E_{j, 0}+\varepsilon E_{j, 1}+\varepsilon^{2} E_{j, 2}+\ldots$

$S_{i}=S_{i, 0}+\varepsilon S_{i, 1}+\varepsilon^{2} S_{i, 2}+\ldots$

where $\varepsilon$ is a very small number.

Expanding Eq. (5), and keeping the first two orders of $\varepsilon$, gives

$$
\varepsilon: C_{i j, 1}\left(1+\sum_{k=1}^{k=J} \frac{E_{k, 0}}{K_{\mathrm{S}, i k}}+\sum_{k=1}^{k=I} \frac{S_{k, 0}}{K_{\mathrm{S}, k j}}\right)=\frac{S_{i, \mathrm{~T}} E_{j, \mathrm{~T}}}{\varepsilon K_{\mathrm{S}, i j}}
$$


Table A1. Symbols used in paper, their definitions and corresponding units.

\begin{tabular}{|c|c|c|}
\hline Symbol & Definition & Unit \\
\hline$B_{j}$ & Biomass of microbe $j$ & $\mathrm{~mol} \mathrm{C} \mathrm{m}^{-3}$ or $\mathrm{g} \mathrm{C}$ \\
\hline$C, C_{i j}$ & Enzyme-substrate complex & $\mathrm{mol} \mathrm{C} \mathrm{m}-3$ \\
\hline$C_{i j, 1}, C_{i j, 2}$ & Scaled first and second order accurate terms of complex $C_{i j}$ & $\mathrm{~mol} \mathrm{C} \mathrm{m}^{-3}$ \\
\hline$D_{i}$ & Diffusivity of substrate $S_{i}$ in water & $\mathrm{m}^{2} \mathrm{~s}^{-1}$ \\
\hline$E, E_{j}$ & Free enzyme abundance & $\mathrm{mol} \mathrm{m}^{-3}$ \\
\hline$E_{j, 0}, E_{j, 1}, E_{j, 2}$ & Zero, first, and second order accurate terms of enzyme $E_{j}$ & $\mathrm{~mol} \mathrm{~m}^{-3}$ \\
\hline$\Delta H$ & Activation energy & $\mathrm{J} \mathrm{mol}^{-1}$ \\
\hline$I_{k, \mathrm{~T}}$ & Total abundance of inhibitor $k$ & $\mathrm{~mol} \mathrm{~m}^{-3}$ \\
\hline$J_{\cos t}$ & Cost function & unitless \\
\hline$k_{1}^{+}, k_{i j, 1}^{+}$ & Forward reaction coefficients & $\mathrm{m}^{3} \mathrm{~mol}^{-1} \mathrm{~s}^{-1}$ \\
\hline$k_{1}^{-}, k_{i j, 1}^{-}$ & Backward reaction coefficients & $\mathrm{s}^{-1}$ \\
\hline$k_{2}^{+}, k_{i j, 2}^{+}$ & Forward reaction coefficients & $\mathrm{s}^{-1}$ \\
\hline$K_{\mathrm{S}}, K_{\mathrm{S}, i j}, \hat{K}_{\mathrm{S}, i 1}, \tilde{K}_{\mathrm{S}, i j}$ & Substrate affinity coefficients & $\mathrm{mol} \mathrm{C} \mathrm{m}{ }^{-3}$ \\
\hline$K_{I, i j}, K_{I, i j k}$ & Inhibitory coefficients & $\operatorname{mol~C~m}{ }^{-3}$ \\
\hline$n_{j}$ & Cell number density of microbe $j$ & cells $\mathrm{m}^{-3}$ \\
\hline$P_{i j}$ & Product from degradation of complex $C_{i j}$ & $\mathrm{~mol} \mathrm{C} \mathrm{m}^{-3}$ or $\mathrm{g} \mathrm{C}$ \\
\hline$r_{\mathrm{c}, j}$ & Mean cell size of microbe $j$ & $\mathrm{~m}$ \\
\hline$R$ & Universal gas constant & $\mathrm{J} \mathrm{K}^{-1} \mathrm{~mol}^{-1}$ \\
\hline$S, S_{i}, \tilde{S}_{i}$ & Free substrate abundance & $\mathrm{mol} \mathrm{C} \mathrm{m}{ }^{-3}$ or $\mathrm{g} \mathrm{C}$ \\
\hline$S_{i, 0}, S_{i, 1}$ & Zero, first, and second order accurate terms of substrate $S_{i}$ & $\mathrm{~mol} \mathrm{~m}^{-3}$ \\
\hline$S_{i, \mathrm{~T}}$ & Total substrate abundance & $\mathrm{mol} \mathrm{m}^{-3}$ \\
\hline$T$ & Temperature & $\mathrm{K}$ \\
\hline$v$ & Substrate uptake rate & $\mathrm{mol} \mathrm{m}^{-3} \mathrm{~s}^{-1}$ \\
\hline$V_{\max }$ & Maximum substrate uptake rate & $\mathrm{mol} \mathrm{m}^{-3} \mathrm{~s}^{-1}$ \\
\hline$\alpha_{k}$ & Active fraction of the enzyme $k$ & unitless \\
\hline$\varepsilon$ & Small number & unitless \\
\hline$\mu_{i j}$ & Biomass yield when microbe $B_{j}$ feeds on $S_{i}$ & unitless \\
\hline$\psi_{j}$ & Area-based transporter density of cell $j$ & $\mathrm{~mol} \mathrm{~m}^{-2}$ \\
\hline$\sigma_{\text {LIC }}$ & Standard deviation of lignocellulose index & unitless \\
\hline$\sigma_{\text {Mass }}$ & Standard deviation of the remaining organic biomass & unitless \\
\hline$\gamma_{j}$ & Respiration rate of microbe $j$ & $\mathrm{~h}^{-1}$ or $\mathrm{d}^{-1}$ \\
\hline$\Phi_{\mathrm{D}}$ & Substrate flux & $\mathrm{mol} \mathrm{m}^{-3} \mathrm{~s}^{-1}$ \\
\hline$\Phi_{\mathrm{E}}$ & Changing rate of new enzymes (transporters) & $\mathrm{mol} \mathrm{m}^{-3} \mathrm{~s}^{-1}$ \\
\hline
\end{tabular}

$$
\begin{aligned}
& \varepsilon^{2}: C_{i j, 2}\left(1+\sum_{k=1}^{k=J} \frac{E_{k, 0}}{K_{\mathrm{S}, i k}}+\sum_{k=1}^{k=I} \frac{S_{k, 0}}{K_{\mathrm{S}, k j}}\right) \\
& +C_{i j, 1}\left(\sum_{k=1}^{k=J} \frac{E_{k, 1}}{K_{\mathrm{S}, i k}}+\sum_{k=1}^{k=I} \frac{S_{k, 1}}{K_{\mathrm{S}, k j}}+\sum_{m=1, l=1}^{m=I, l=J} \frac{K_{\mathrm{S}, n l} C_{m l, 1}}{K_{\mathrm{S}, i l} K_{\mathrm{S}, m j}}\right)=0
\end{aligned}
$$

where the third subscript on $C_{i j}$ indicates the associated order of $\varepsilon$. Substituting Eq. (A5) into Eq. (A3) gives

$$
C_{i j, 1} \approx \frac{S_{i, \mathrm{~T}} E_{j, \mathrm{~T}}}{\varepsilon K_{\mathrm{S}, i j}\left(1+\sum_{k=1}^{k=J} \frac{E_{k, 0}}{K_{\mathrm{S}, i k}}+\sum_{k=1}^{k=I} \frac{S_{k, 0}}{K_{\mathrm{S}, k j}}\right)}
$$

$$
\begin{aligned}
C_{i j, 2} & =\frac{C_{i j, 1}}{K_{\mathrm{S}, i j}\left(1+\sum_{k=1}^{k=J} \frac{E_{k, 0}}{K_{\mathrm{S}, i k}}+\sum_{k=1}^{k=I} \frac{S_{k, 0}}{K_{\mathrm{S}, k j}}\right)} \\
& \sum_{n=1, l=1}^{n=I, l=J} C_{n l, 1} K_{\mathrm{S}, i j}\left(\frac{K_{\mathrm{S}, i l}+K_{\mathrm{S}, n j}-K_{\mathrm{S}, n l}}{K_{\mathrm{S}, i l} K_{\mathrm{S}, n j}}\right) .
\end{aligned}
$$

Therefore, by using $E_{j, \mathrm{~T}}=E_{j, 0}$ and $S_{i, \mathrm{~T}}=S_{i, 0}$ at the zero order approximation, Eq. (A6a) is equivalent to Eq. (13) in the main text. The derivation of Eq. (A6b) is given in the Supplement.

Because of the many unspecified parameters (prior to a specific application), we were not able to identify a best estimate of the condition when Eq. (A6a) is exactly first order accurate. However, from Eq. (A6b), we obtain a crude condition 


$$
\begin{aligned}
& \left(\frac{K_{\mathrm{S}, i j}}{S_{i, 0}}+\sum_{k=1}^{k=J} \frac{K_{\mathrm{S}, i j}}{K_{\mathrm{S}, i k}} \frac{E_{k, 0}}{S_{i, 0}}+\sum_{k=1}^{k=I} \frac{K_{\mathrm{S}, i j}}{K_{\mathrm{S}, k j}} \frac{S_{k, 0}}{S_{i, 0}}\right) \\
& \left(\frac{K_{\mathrm{S}, i j}}{E_{j, 0}}+\sum_{k=1}^{k=J} \frac{K_{\mathrm{S}, i j}}{K_{\mathrm{S}, i k}} \frac{E_{k, 0}}{E_{j, 0}}+\sum_{k=1}^{k=I} \frac{K_{\mathrm{S}, i j}}{K_{\mathrm{S}, k j}} \frac{S_{k, 0}}{E_{j, 0}}\right) \gg 1
\end{aligned}
$$

Condition Eq. (A7) holds if $S_{i, 0} \gg E_{j, 0}$ or $S_{i, 0} \ll E_{j, 0}$. Even if $S_{i, 0} \approx E_{j, 0}$, Eq. (A7) may still hold because of the many possible parameter combinations in a complicated reaction network.

While it is cumbersome to verify Eq. (A6) for all combinations of substrate and consumer, under the single-substrate and single-consumer condition, we have

$$
\begin{aligned}
C_{11} & =\varepsilon C_{11,1}+\varepsilon^{2} C_{11,2} \\
& =\frac{S_{1, \mathrm{~T}} E_{1, \mathrm{~T}}}{K_{\mathrm{S}, 11}+S_{1, \mathrm{~T}}+E_{1, \mathrm{~T}}}\left[1+\frac{S_{1, \mathrm{~T}} E_{1, \mathrm{~T}}}{\left(K_{\mathrm{S}, 11}+S_{1, \mathrm{~T}}+E_{1, \mathrm{~T}}\right)^{2}}\right]
\end{aligned}
$$

which is equivalent to Eq. (3) in Cha and Cha (1965) when truncated to second order accuracy.

\section{Appendix B}

\section{An alternate analytic approximation}

Substituting the mass balance relationships Eqs. (A1) and (A2) into Eq. (6), one has:

$$
\left(S_{i, \mathrm{~T}}-\sum_{k=1}^{k=J} C_{i k}\right)\left(E_{j, \mathrm{~T}}-\sum_{k=1}^{k=I} C_{k j}\right)=K_{\mathrm{S}, i j} C_{i j}
$$

Then by expanding Eq. (B1) and ignoring quadratic terms, one obtains a set of linear equations:

$$
K_{\mathrm{S}, i j} C_{i j}+S_{i, \mathrm{~T}} \sum_{k=1}^{k=J} C_{i k}+E_{j, \mathrm{~T}} \sum_{k=1}^{k=I} C_{k j}=S_{i, \mathrm{~T}} E_{j, \mathrm{~T}}
$$

where we again used the zero order approximation $E_{j, \mathrm{~T}}=$ $E_{j, 0}$ and $S_{i, \mathrm{~T}}=S_{i, 0}$.

Since we have not been able to find an analytical solution to Eq. (B2), we attempted to solve it using existing linear algebra packages. This effort turned out to be numerically very difficult, and often resulted in unrealistic and negative complex concentrations. However, using results derived by De Boer and Perelson (1995), we developed an approximate solution:

$$
C_{i j}=\frac{S_{i, \mathrm{~T}} E_{j, \mathrm{~T}}}{K_{\mathrm{S}, i j}+\sum_{k=1}^{k=I} S_{k, \mathrm{~T}} \frac{E_{j, \mathrm{~T}}+K_{\mathrm{S}, i j}}{E_{j, \mathrm{~T}}+K_{\mathrm{S}, k j}}+\sum_{k=1}^{k=J} E_{k, \mathrm{~T}} \frac{S_{i, \mathrm{~T}}+K_{\mathrm{S}, i j}}{S_{i, \mathrm{~T}}+K_{\mathrm{S}, i k}}}
$$

which satisfies Eq. (B2) exactly when $I=1$ or $J=1$. We evaluated Eq. (B3) with random sampling tests, and found it was generally inferior to Eq. (13) (results not shown).

\section{Appendix C}

\section{The MM kinetics based approximation to the EC solution}

The MM kinetics based representation of the enzymesubstrate complex $C_{i j}$ is

$$
C_{i j}=\frac{S_{i, \mathrm{~T}} E_{j, \mathrm{~T}}}{K_{\mathrm{S}, i j}+S_{i, \mathrm{~T}}}
$$

The solution Eq. (C1) is then scaled linearly to satisfy the mass constraint:

$\sum_{k=1}^{k=I} C_{k j} \leq E_{j, \mathrm{~T}}$

$\sum_{k=1}^{k=J} C_{i k} \leq S_{i, \mathrm{~T}}$

We point out that Eqs. (C2) have been implemented differently from other studies, e.g., Moorhead and Sinsabaugh (2006; GDM), Riley et al. (2011; CLM4Me), and Allison (2012; DEMENT). Those studies imposed the constraint on total substrate flux within a single time step rather than on the overall enzyme-substrate complexes. It is only with Eqs. (C2) that MM and ECA-ML kinetics were able to model the adsorption surface effect on substrate dynamics, but they were less accurate than the ECA kinetics, as we have demonstrated in the main text (see discussions on scenario S3B1M1 in Sect. 3.2).

\section{Supplementary material related to this article is available online at http://www.biogeosciences.net/10/ 8329/2013/bg-10-8329-2013-supplement.pdf.}

Acknowledgements. This research was supported by the Director, Office of Science, Office of Biological and Environmental Research of the US Department of Energy, under contract no. DE-AC0205CH11231, as part of their Regional and Global Climate Modeling Program; and by the Next-Generation Ecosystem Experiments (NGEE Arctic) project, supported by the Office of Biological and Environmental Research in the DOE Office of Science under contract no. DE-AC02-05CH11231.

Edited by: G. Herndl 


\section{References}

Aber, J. D., Melillo, J. M., and Mcclaugherty, C. A.: Predicting long-term patterns of mass-loss, nitrogen dynamics, and soil organic-matter formation from initial fine litter chemistry in temperate forest ecosystems, Can. J. Bot., 68, 2201-2208, 1990.

Abrams, P. A. and Ginzburg, L. R.: The nature of predation: prey dependent, ratio dependent or neither?, Trends Ecol. Evol., 15, 337-341, doi:10.1016/S0169-5347(00)01908-X, 2000.

Allison, S. D.: A trait-based approach for modelling microbial litter decomposition, Ecol. Lett., 15, 1058-1070, doi:10.1111/j.14610248.2012.01807.x, 2012.

Allison, S. D., Wallenstein, M. D., and Bradford, M. A.: Soil-carbon response to warming dependent on microbial physiology, Nat. Geosci., 3, 336-340, doi:10.1038/Ngeo846, 2010.

Andren, O. and Paustian, K.: Barley straw decomposition in the field - a comparison of models, Ecology, 68, 1190-1200, doi:10.2307/1939203, 1987.

Arditi, R. and Ginzburg, L. R.: Coupling in predator prey dynamics - ratio-dependence, J. Theor. Biol., 139, 311-326, doi:10.1016/S0022-5193(89)80211-5, 1989.

Armstrong, R. A.: Nutrient uptake rate as a function of cell size and surface transporter density: A Michaelis-like approximation to the model of Pasciak and Gavis, Deep-Sea Res Pt. I, 55, 13111317, doi:10.1016/J.Dsr.2008.05.004, 2008.

Balser, T. C. and Wixon, D. L.: Investigating biological control over soil carbon temperature sensitivity, Glob. Change Biol., 15, 2935-2949, doi:10.1111/J.1365-2486.2009.01946.X, 2009.

Bauer, J., Herbst, M., Huisman, J. A., Weihermuller, L., and Vereecken, H.: Sensitivity of simulated soil heterotrophic respiration to temperature and moisture reduction functions, Geoderma, 145, 17-27, doi:10.1016/J.Geoderma.2008.01.026, 2008.

Bender, C. M. and Orzag, S. A.: Advanced Mathematical Methods for Scientists and Engineers, Springer-Verlag, New York, 1999.

Berg, H. C. and Purcell, E. M.: Physics of Chemoreception, Biophys. J., 20, 193-219, 1977.

Berg, B. and Staaf, H.: Decomposition rate and chemical changes of Scots pine litter. II. Influence of chemical composition, Ecol. Bull., 32, 373-390, 1980.

Berg, B., Hannus, K., Popoff, T., and Theander, O.: Changes in organic-chemical components of needle litter during decomposition - long-term decomposition in a scots pine forest .1., Can. J. Bot., 60, 1310-1319, 1982.

Beven, K.: A manifesto for the equifinality thesis, Journal of Hydrology, 320, 18-36, doi:10.1016/J.Jhydrol.2005.07.007, 2006.

Bonachela, J. A., Raghib, M., and Levin, S. A.: Dynamic model of flexible phytoplankton nutrient uptake, P. Natl. Acad. Sci. USA, 108, 20633-20638, doi:10.1073/Pnas.1118012108, 2011.

Bonner, W. D., Gore, W. L., and Yost, D. M.: The thermal reaction between gaseous iodine monochloride and hydrogen, J. Am. Chem. Soc., 57, 2723-2724, doi:10.1021/Ja01315a502, 1935.

Borghans, J. A. M. and Deboer, R. J.: A minimal model for T-cell vaccination, P. Roy. Soc. B.-Biol. Sci., 259, 173-178, doi:10.1098/Rspb.1995.0025, 1995.

Borghans, J. A. M., DeBoer, R. J., and Segel, L. A.: Extending the quasi-steady state approximation by changing variables, B. Math. Biol., 58, 43-63, doi:10.1007/Bf02458281, 1996.

Bouskill, N. J., Tang, J. Y., Riley, W. J., and Brodie, E. L.: Traitbased representation of biological nitrification: model develop- ment, testing, and predicted community composition, Front. Microbiol., 3, 364, doi:10.3389/fmicb.2012.00364, 2012.

Broekhuizen, N., Rickard, G. J., Bruggeman, J., and Meister, A.: An improved and generalized second order, unconditionally positive, mass conserving integration scheme for biochemical systems, Appl. Numer. Math., 58, 319-340, doi:10.1016/J.Apnum.2006.12.002, 2008.

Burnett, T.: Influences of natural temperatures and controlled host densities on oviposition of an insect parasite, Physiol. Zool., 27, 239-258, 1954.

Campbell, A.: Conditions for existence of bacteriophage, Evolution, 15, 153-165, doi:10.2307/2406076, 1961.

Caperon, J.: Population growth in micro-organisms limited by food supply, Ecology, 48, 715-722, doi:10.2307/1933728, 1967.

Cha, S. and Cha, C. J. M.: Kinetics of cyclic enzyme systems, Mol. Pharmacol., 1, 178-189, 1965.

Childs, R. E. and Bardsley, W. G.: Steady-state kinetics of peroxidase with 2,2'-Azino-Di-(3-Ethylbenzthiazoline-6-Sulphonic Acid) as chromogen, Biochem. J., 145, 93-103, 1975.

Choy, K. K. H., Porter, J. F., and McKay, G.: Langmuir isotherm models applied to the multicomponent sorption of acid dyes from effluent onto activated carbon, J. Chem. Eng. Data, 45, 575-584, doi:10.1021/Je9902894, 2000.

Ciliberto, A., Capuani, F., and Tyson, J. J.: Modeling networks of coupled enzymatic reactions using the total quasisteady state approximation, Plos Comput. Biol., 3, 463-472, doi:10.1371/Journal.Pcbi.0030045, 2007.

Cornish-Bowden, A.: Fundamentals of Enzyme Kinetics, rev. ed., Portland Press, London, 1995.

Davidson, E. A. and Janssens, I. A.: Temperature sensitivity of soil carbon decomposition and feedbacks to climate change, Nature, 440, 165-173, doi:10.1038/Nature04514, 2006.

Davidson, E. A., Samanta, S., Caramori, S. S., and Savage, K.: The dual Arrhenius and Michaelis-Menten kinetics model for decomposition of soil organic matter at hourly to seasonal time scales, Glob. Change Biol., 18, 371-384, doi:10.1111/J.13652486.2011.02546.X, 2012.

De Boer, R. J. and Perelson, A. S.: T-cell repertoires and competitive-exclusion, J. Theor. Biol., 169, 375-390, doi:10.1006/Jtbi.1994.1160, 1994.

De Boer, R. J. and Perelson, A. S.: Towards a general function describing T-cell proliferation, J. Theor. Biol., 175, 567-576, doi:10.1006/Jtbi.1995.0165, 1995.

Dilly, O. and Munch, J. C.: Microbial biomass content, basal respiration and enzyme activities during the course of decomposition of leaf litter in a black alder (Alnus glutinosa (L) Gaertn) forest, Soil Biol. Biochem., 28, 1073-1081, doi:10.1016/00380717(96)00075-2, 1996.

Druhan, J. L., Steefel, C. I., Molins, S., Williams, K. H., Conrad, M. E., and DePaolo, D. J.: Timing the onset of sulfate reduction over multiple subsurface acetate amendments by measurement and modeling of sulfur isotope fractionation, Environ. Sci. Technol., 46, 8895-8902, doi:10.1021/Es302016p, 2012.

Dybzinski, R., Farrior, C., Wolf, A., Reich, P. B., and Pacala, S. W.: Evolutionarily stable strategy carbon allocation to foliage, wood, and fine roots in trees competing for light and nitrogen: an analytically tractable, individual-based model and quantitative comparisons to data, Am. Nat., 177, 153-166, doi:10.1086/657992, 2011. 
Eyring, H.: The activated complex and the absolute rate of chemical reactions, Chem. Rev., 17, 65-77, doi:10.1021/Cr60056a006, 1935.

Eyring, H.: The activated complex in chemical reactions, J. Chem. Phys., 3, 107-115, doi:10.1063/1.1749604, 1935.

Felmy, A. R., Girvin, D. C., and Jenne, E. A.: MINTEQ: A computer program for calculating aqueous geochemical equilibria, EPA-600/3-84-032, Office Res. Dev., USEPA, Athens, GA, 1984.

Follows, M. J., Dutkiewicz, S., Grant, S., and Chisholm, S. W.: Emergent biogeography of microbial communities in a model ocean, Science, 315, 1843-1846, doi:10.1126/Science.1138544, 2007.

Ginzburg, L. R. and Akcakaya, H. R.: Consequences of ratiodependent predation for steady-state properties of ecosystems, Ecology, 73, 1536-1543, doi:10.2307/1940006, 1992.

Goldbeter, A. and Koshland, D. E.: An amplified sensitivity arising from covalent modification in biological-systems, P. Natl. Acad. Sci.-Biol., 78, 6840-6844, doi:10.1073/Pnas.78.11.6840, 1981.

Grant, R. F., Juma, N. G., and Mcgill, W. B.: Simulation of carbon and nitrogen transformations in soil - mineralization, Soil Biol. Biochem., 25, 1317-1329, doi:10.1016/0038-0717(93)90046-E, 1993.

Gu, C. H., Maggi, F., Riley, W. J., Hornberger, G. M., Xu, T., Oldenburg, C. M., Spycher, N., Miller, N. L., Venterea, R. T., and Steefel, C.: Aqueous and gaseous nitrogen losses induced by fertilizer application, J. Geophys. Res.-Biogeo., 114, G01006, doi:10.1029/2008jg000788, 2009.

Hall, S. R.: Stoichiometrically explicit competition between grazers: Species replacement, coexistence, and priority effects along resource supply gradients, Am. Nat., 164, 157-172, doi:10.1086/422201, 2004.

Herman, J., Moorhead, D., and Berg, B.: The relationship between rates of lignin and cellulose decay in aboveground forest litter, Soil Biol. Biochem., 40, 2620-2626, doi:10.1016/J.Soilbio.2008.07.003, 2008.

Holling, C. S.: The components of predation as revealed by a study of small-mammal predation of the european pine sawfly, Can. Entomol., 91, 293-320, doi:10.4039/Ent9129-7, 1959.

Jacobson, M. Z.: Studying the effects of calcium and magnesium on size-distributed nitrate and ammonium with EQUISOLV II, Atmos. Environ., 33, 3635-3649, doi:10.1016/S13522310(99)00105-3, 1999.

Jacobson, M. Z., Tabazadeh, A., and Turco, R. P.: Simulating equilibrium within aerosols and nonequilibrium between gases and aerosols, J. Geophys. Res.-Atmos., 101, 9079-9091, doi:10.1029/96jd00348, 1996.

Jenkinson, D. S. and Coleman, K.: The turnover of organic carbon in subsoils. Part 2. Modelling carbon turnover, Eur. J. Soil Sci., 59, 400-413, doi:10.1111/J.1365-2389.2008.01026.X, 2008.

Jennings, A. A., Kirkner, D. J., and Theis, T. L.: Multicomponent equilibrium chemistry in groundwater quality models, Water Resour. Res., 18, 1089-1096, doi:10.1029/Wr018i004p01089, 1982.

Jin, Q. and Bethke, C. M.: The thermodynamics and kinetics of microbial metabolism, Am. J. Sci., 307, 643-677, doi:10.2475/04.2007.01, 2007.
Karp-Boss, L., Boss, E., and Jumars, P. A.: Nutrient fluxes to planktonic osmotrophs in the presence of fluid motion, Oceanogr. Mar. Biol., 34, 71-107, 1996.

Keeler, B. L., Hobbie, S. E., and Kellogg, L. E.: Effects of long-term nitrogen addition on microbial enzyme activity in eight forested and grassland sites: implications for litter and soil organic matter decomposition, Ecosystems, 12, 1-15, doi:10.1007/S10021-0089199-Z, 2009.

Klotzbucher, T., Kaiser, K., Guggenberger, G., Gatzek, C., and Kalbitz, K.: A new conceptual model for the fate of lignin in decomposing plant litter, Ecology, 92, 1052-1062, 2011.

Koen-Alonso, M.: A process-oriented approach to the multispecies functional response, in: From Energetics to Ecosystems: The Dynamics and Structure of Ecological Systems, edited by: Rooney, N., McCann, M. S., and Noakes, D. L. G., Springer, Dordrecht, The Netherlands, 1-36, 2007.

Kooijman, S. A. L. M.: The Synthesizing Unit as model for the stoichiometric fusion and branching of metabolic fluxes, Biophys. Chem., 73, 179-188, doi:10.1016/S0301-4622(98)001628, 1998.

Kooijman, S. A. L. M. and Troost, T. A.: Quantitative steps in the evolution of metabolic organisation as specified by the Dynamic Energy Budget theory, Biol. Rev., 82, 113-142, doi:10.1111/J.1469-185x.2006.00006.X, 2007.

Koven, C. D., Riley, W. J., Subin, Z. M., Tang, J. Y., Torn, M. S., Collins, W. D., Bonan, G. B., Lawrence, D. M., and Swenson, S. C.: The effect of vertically resolved soil biogeochemistry and alternate soil $\mathrm{C}$ and $\mathrm{N}$ models on C dynamics of CLM4, Biogeosciences, 10, 7109-7131, doi:10.5194/bg-10-7109-2013, 2013.

Kratina, P., Vos, M., Bateman, A., and Anholt, B. R.: Functional responses modified by predator density, Oecologia, 159, 425433, doi:10.1007/S00442-008-1225-5, 2009.

Kumar, A. and Josic, K.: Reduced models of networks of coupled enzymatic reactions, J. Theor. Biol., 278, 87-106, doi:10.1016/J.Jtbi.2011.02.025, 2011.

Ladd, J. N., Amato, M., Zhou, L. K., and Schultz, J. E.: Differentialeffects of rotation, plant residue and nitrogen-fertilizer on microbial biomass and organic-matter in an Australian Alfisol, Soil Biol. Biochem., 26, 821-831, doi:10.1016/0038-0717(94)902984, 1994.

Lambers, H., Mougel, C., Jaillard, B., and Hinsinger, P.: Plantmicrobe-soil interactions in the rhizosphere: an evolutionary perspective, Plant Soil, 321, 83-115, doi:10.1007/S11104-0090042-X, 2009.

Legovic, T. and Cruzado, A.: A model of phytoplankton growth on multiple nutrients based on the Michaelis-Menten-Monod uptake, Droop's growth and Liebig's law, Ecol. Model., 99, 19-31, doi:10.1016/S0304-3800(96)01919-9, 1997.

Li, C. S., Frolking, S., and Frolking, T. A.: A model of nitrous-oxide evolution from soil driven by rainfall events .1. model structure and sensitivity, J. Geophys. Res.-Atmos., 97, 9759-9776, 1992.

Lindeman, R. L.: The trophic-dynamic aspect of ecology, Ecology, 23, 399-418, doi:10.2307/1930126, 1942.

Litchman, E., Klausmeier, C. A., Schofield, O. M., and Falkowski, P. G.: The role of functional traits and trade-offs in structuring phytoplankton communities: scaling from cellular to ecosystem level, Ecol. Lett., 10, 1170-1181, doi:10.1111/J.14610248.2007.01117.X, 2007. 
Liu, Y.: Overview of some theoretical approaches for derivation of the Monod equation, Appl. Microbiol. Biotech., 73, 1241-1250, 2007.

Lotka, A. J.: Contribution to quantitative parasitology, J. Wash. Acad. Sci. 13, 152-158, 1923.

Machinet, G. E., Bertrand, I., and Chabbert, B.: Assessment of Lignin-Related Compounds in Soils and Maize Roots by Alkaline Oxidations and Thioacidolysis, Soil Sci. Soc. Am. J., 75, 542-552, doi:10.2136/Sssaj2010.0222, 2011.

Maggi, F. and Riley, W. J.: Transient competitive complexation in biological kinetic isotope fractionation explains nonsteady isotopic effects: Theory and application to denitrification in soils, J. Geophys. Res.-Biogeo., 114, G04012, doi:10.1029/2008jg000878, 2009.

Maggi, F., Gu, C., Riley, W. J., Hornberger, G. M., Venterea, R. T., Xu, T., Spycher, N., Steefel, C., Miller, N. L., and Oldenburg, C. M.: A mechanistic treatment of the dominant soil nitrogen cycling processes: Model development, testing, and application, J. Geophys. Res.-Biogeo., 113, G02016, doi:10.1029/2007jg000578, 2008.

Magill, A. H. and Aber, J. D.: Long-term effects of experimental nitrogen additions on foliar litter decay and humus formation in forest ecosystems, Plant Soil, 203, 301-311, doi:10.1023/A:1004367000041, 1998.

Mayes, M. A., Heal, K. R., Brandt, C. C., Phillips, J. R., and Jardine, P. M.: Relation between soil order and sorption of dissolved organic carbon in temperate subsoils, Soil Sci. Soc. Am. J., 76, 1027-1037, doi:10.2136/Sssaj2011.0340, 2012.

McCarty, P. L.: Thermodynamic electron equivalents model for bacterial yield prediction: Modifications and comparative evaluations, Biotechnol. Bioeng., 97, 377-388, doi:10.1002/Bit.21250, 2007.

McGill, B. J. and Brown, J. S.: Evolutionary game theory and adaptive dynamics of continuous traits, Annu. Rev. Ecol. Evol. S., 38, 403-435, doi:10.1146/Annurev.Ecolsys.36.091704.175517, 2007.

McGuire, A. D., Melillo, J. M., Kicklighter, D. W., Pan, Y. D., Xiao, X. M., Helfrich, J., Moore, B., Vorosmarty, C. J., and Schloss, A. L.: Equilibrium responses of global net primary production and carbon storage to doubled atmospheric carbon dioxide: Sensitivity to changes in vegetation nitrogen concentration, Global Biogeochem. Cy., 11, 173-189, doi:10.1029/97gb00059, 1997.

Melillo, J. M., Aber, J. D., and Muratore, J. F.: Nitrogen and lignin control of hardwood leaf litter decomposition dynamics, Ecology, 63, 621-626, doi:10.2307/1936780, 1982.

Melillo, J. M., Aber, J. D., Linkins, A. E., Ricca, A., Fry, B., and Nadelhoffer, K. J.: Carbon and nitrogen dynamics along the decay continuum - plant litter to soil organic-matter, Plant Soil, 115, 189-198, doi:10.1007/Bf02202587, 1989.

Michaelis, L. and Menten, M. L.: The kenetics of the inversion effect, Biochem. Z., 49, 333-369, 1913.

Machinet, G. E., Bertrand, I., Barriere, Y., Chabbert, B., and Recous, S.: Impact of plant cell wall network on biodegradation in soil: Role of lignin composition and phenolic acids in roots from 16 maize genotypes, Soil Biol. Biochem., 43, 1544-1552, doi:10.1016/J.Soilbio.2011.04.002, 2011.

Molins, S., Trebotich, D., Steefel, C. I., and Shen, C. P.: An investigation of the effect of pore scale flow on average geochemical reaction rates using direct numerical simulation, Water Resour. Res., 48, W03527, doi:10.1029/2011wr011404, 2012.

Moorhead, D. L. and Sinsabaugh, R. L.: A theoretical model of litter decay and microbial interaction, Ecol. Monogr., 76, 151-174, doi:10.1890/0012-9615(2006)076[0151:Atmold]2.0.Co;2, 2006.

Murdoch, W. W.: Functional Response of Predators, J. Appl. Ecol., 10, 335-342, 1973.

Osono, T.: Ecology of ligninolytic fungi associated with leaf litter decomposition, Ecol. Res., 22, 955-974, doi:10.1007/S11284007-0390-Z, 2007.

Parton, W. J., Stewart, J. W. B., and Cole, C. V.: Dynamics of C, N, $\mathrm{P}$ and $\mathrm{S}$ in grassland soils - a model, Biogeochemistry, 5, 109131, doi:10.1007/Bf02180320, 1988.

Pasciak, W. J. and Gavis, J.: Transport limitation of nutrient uptake in phytoplankton, Limnol. Oceanogr., 19, 881-898, 1974.

Pasciak, W. J. and Gavis, J.: Transport limited nutrient uptake rates in Ditylum-Brightwellii, Limnol. Oceanogr., 20, 604-617, 1975.

Persson, L., Leonardsson, K., de Roos, A. M., Gyllenberg, M., and Christensen, B.: Ontogenetic scaling of foraging rates and the dynamics of a size-structured consumer-resource model, Theor. Popul. Biol., 54, 270-293, doi:10.1006/Tpbi.1998.1380, 1998.

Pilinis, C., Seinfeld, J. H., and Seigneur, C.: Mathematical modeling of the dynamics of multicomponent atmospheric aerosols, Atmos. Environ., 21, 943-955, doi:10.1016/0004-6981(87)900904, 1987.

Reynolds, H. L. and Pacala, S. W.: An analytical treatment of rootto-shoot ratio and plant competition for soil nutrient and light, Am. Nat., 141, 51-70, doi:10.1086/285460, 1993.

Riley, W. J. and Matson, P. A.: NLOSS: A mechanistic model of denitrified N2O and N-2 evolution from soil, Soil Sci., 165, 237249, doi:10.1097/00010694-200003000-00006, 2000.

Riley, W. J., Subin, Z. M., Lawrence, D. M., Swenson, S. C., Torn, M. S., Meng, L., Mahowald, N. M., and Hess, P.: Barriers to predicting changes in global terrestrial methane fluxes: analyses using CLM4Me, a methane biogeochemistry model integrated in CESM, Biogeosciences, 8, 1925-1953, doi:10.5194/bg-8-19252011, 2011.

Rodrigo, A., Recous, S., Neel, C., and Mary, B.: Modelling temperature and moisture effects on $\mathrm{C}-\mathrm{N}$ transformations in soils: comparison of nine models, Ecol. Model., 102, 325-339, doi:10.1016/S0304-3800(97)00067-7, 1997.

Saggar, S., Parshotam, A., Sparling, G. P., Feltham, C. W., and Hart, P. B. S.: C-14-labelled ryegrass turnover and residence times in soils varying in clay content and mineralogy, Soil Biol. Biochem., 28, 1677-1686, doi:10.1016/S0038-0717(96)002507, 1996.

Schenk, D., Bersier, L. F., and Bacher, S.: An experimental test of the nature of predation: neither prey- nor ratiodependent, J. Anim. Ecol., 74, 86-91, doi:10.1111/J.13652656.2004.00900.X, 2005.

Schimel, J. P., Wetterstedt, J. A. M., Holden, P. A., and Trumbore, S. E.: Drying/rewetting cycles mobilize old C from deep soils from a California annual grassland, Soil Biol. Biochem., 43, 11011103, doi:10.1016/J.Soilbio.2011.01.008, 2011.

Schnell, S. and Maini, P. K.: Enzyme kinetics at high enzyme concentration, B Math. Biol., 62, 483-499, doi:10.1006/Bulm.1999.0163, 2000. 
Schnell, S. and Mendoza, C.: Enzyme kinetics of multiple alternative substrates, J. Math. Chem., 27, 155-170, doi:10.1023/A:1019139423811, 2000.

Segel, L. A. and Slemrod, M.: The quasi-steady-state assumption - a case-study in perturbation, Siam. Rev., 31, 446-477, doi:10.1137/1031091, 1989.

Sposito, G. and Coves, J.: SOILCHEM: A computer program for the calculation of chemical spcciation in soils, Keamey Found. Soil Sci., Univ. California, Riverside, 1988.

Suzuki, I., Lizama, H. M., and Tackaberry, P. D.: Competitiveinhibition of ferrous iron oxidation by thiobacillus-ferrooxidans by increasing concentrations of cells, Appl. Environ. Microbiol., 55, 1117-1121, 1989.

Taylor, K. E.: Summarizing multiple aspects of model performance in a single diagram., J. Geophys. Res.-Atmos, 106, 7183-7192, doi:10.1029/2000jd900719, 2001.

Tang, J. Y. and Zhuang, Q. L.: Equifinality in parameterization of process-based biogeochemistry models: A significant uncertainty source to the estimation of regional carbon dynamics, J. Geophys. Res.-Biogeo., 113, G04010, doi:10.1029/2008jg000757, 2008.

Tang, J. Y., Tang, J., and Wang, Y.: Analytical investigation on 3D non-Boussinesq mountain wave drag for wind profiles with vertical variations, Appl. Math. Mech.-Engl., 28, 317-325, doi:10.1007/S10483-007-0305-Z, 2007.

Thornton, P. E., Lamarque, J. F., Rosenbloom, N. A., and Mahowald, N. M.: Influence of carbon-nitrogen cycle coupling on land model response to $\mathrm{CO}_{2}$ fertilization and climate variability, Global Biogeochem. Cy., 21, Gb4018, doi:10.1029/2006gb002868, 2007.

Tilman, D.: Resource competition between planktonic algae experimental and theoretical approach, Ecology, 58, 338-348, doi:10.2307/1935608, 1977.
Vayenas, D. V. and Pavlou, S.: Chaotic dynamics of a food web in a chemostat, Math. Biosci., 162, 69-84, doi:10.1016/S00255564(99)00044-9, 1999.

Volterra, V.: Variazioni e fluttuazioni del numero d'individui in specie animali conviventi, Mew. Acad. Lincei., 6, 31-113, 1926.

Vrugt, J. A., ter Braak, C. J. F., Clark, M. P., Hyman, J. M., and Robinson, B. A.: Treatment of input uncertainty in hydrologic modeling: Doing hydrology backward with Markov chain Monte Carlo simulation, Water Resour. Res., 44, W00b09, doi:10.1029/2007wr006720, 2008.

Vucetich, J. A., Peterson, R. O., and Schaefer, C. L.: The effect of prey and predator densities on wolf predation, Ecology, 83, 3003-3013, doi:10.2307/3071837, 2002.

Wang, G. S. and Post, W. M.:, A note on the reverse Michaelis-Menten kinetics, Soil Biol. Biochem., 57, 946-949, doi:10.1016/j.soilbio.2012.08.028, 2013.

Wang, G. S., Post, W. M., Mayes, M. A., Frerichs, J. T., and Sindhu, J.: Parameter estimation for models of ligninolytic and cellulolytic enzyme kinetics, Soil Biol. Biochem., 48, 28-38, doi:10.1016/J.Soilbio.2012.01.011, 2012.

Wang, G. S., Post, W. M., and Mayes, M. A.: Development of microbial-enzyme-mediated decomposition model parameters through steady-state and dynamic analyses, Ecol. Appl., 23, 255272, 2013.

Wickings, K., Grandy, A. S., Reed, S. C., and Cleveland, C. C.: The origin of litter chemical complexity during decomposition, Ecol Lett., 15, 1180-1188, doi:10.1111/J.1461-0248.2012.01837.X, 2012.

Williams, P. J.: Validity of Application of Simple Kinetic Analysis to Heterogeneous Microbial Populations, Limnol. Oceanogr., 18, 159-164, 1973. 